NISTIR 6994

\title{
Results from Field Testing of Air Handling Unit and Variable Air Volume Box Fault Detection Tools
}

\author{
Jeffrey Schein \\ Steven T. Bushby \\ Natascha S. Castro
}

U.S. DEPARTMENT OF COMMERCE

National Institute of Standards and Technology

Building Environment Division

Building and Fire Research Laboratory

Gaithersburg, MD 20899-8631

John M. House

Iowa Energy Center

Ames, IA

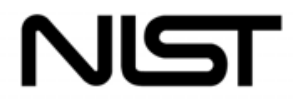

National Institute of Standards and Technology

Technology Administration, U.S. Department of Commerce 
NISTIR 6994

\section{Results from Field Testing of Air Handling Unit and Variable Air Volume Box Fault Detection Tools}

Jeffrey Schein

Steven T. Bushby

Natascha S. Castro

U.S. DEPARTMENT OF COMMERCE National Institute of Standards and Technology

Building Environment Division

Building and Fire Research Laboratory

Gaithersburg, MD 20899-8631

John M. House

Iowa Energy Center

Ames, IA

Prepared for:

Architectural Energy Corporation

Boulder, Colorado

April 2003

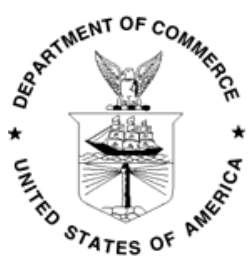

U.S. Department of Commerce

Donald L. Evans, Secretary

Technology Administration

Phillip J. Bond, Under Secretary for Technology National Institute of Standards and Technology Arden L. Bement, Jr., Director 


\begin{abstract}
Building heating, ventilation, and air conditioning (HVAC) equipment routinely fails to satisfy performance expectations envisioned at design. Such failures often go unnoticed for extended periods of time. Additionally, higher expectations are being placed on a combination of different and often conflicting performance measures, such as energy efficiency, indoor air quality, comfort, reliability, limiting peak demand on utilities, etc. To meet these expectations, the processes, systems, and equipment used in both commercial and residential buildings are becoming increasingly sophisticated. This development both necessitates the use of automated diagnostics to ensure fault-free operation and enables diagnostic capabilities for the various building systems by providing a distributed platform that is powerful and flexible enough to perform fault detection and diagnostics (FDD).
\end{abstract}

The purpose of the research effort described in this report is to develop, test, and demonstrate FDD methods that can detect common mechanical faults and control errors in air-handling units (AHUs) and variable-air-volume (VAV) boxes. The tools are intended to be sufficiently simple that they can be embedded in commercial building automation and control systems and rely upon only sensor data and control signals that are commonly available in these systems.

AHU Performance Assessment Rules (APAR) is a diagnostic tool that uses a set of expert rules derived from mass and energy balances to detect faults in air-handling units. Control signals are used to determine the mode of operation for the AHU. A subset of the expert rules corresponding to that mode of operation is then evaluated to determine if there is a mechanical fault or a control problem. VAV box Performance Assessment Control Charts (VPACC) is a diagnostic tool that uses statistical quality control measures to detect faults or control problems in VAV boxes.

This report describes a research study of the application of APAR and VPACC to HVAC systems in real buildings. AHU and VAV box data were collected from several field sites. The study examined the effectiveness of the tools in detecting commonly found mechanical faults and control problems, the reliability of the tools across different building uses and climate regions, and the robustness of the tools in handling data from a variety of HVAC system configurations. APAR and VPACC were both found to be successful at finding a wide variety of faults. Both tools appear to be suitable for embedding in commercial control products.

Key words: BACnet, building automation and control, direct digital control, energy management systems, fault detection and diagnostics, cybernetic building systems

\title{
Acknowledgments
}

This work was supported in part by the California Energy Commission Public Interest Energy Research (PIER) Program. In addition, this project, like any field study, would not have been possible without those individuals who assisted with the data collection aspect of this work. Thanks are due to Mark Levi and Stephen May of the U.S. General Services Administration Region IX, Louis Coughenour of Enovity, Jim Butler, Olav P. Hegland, and Robert Veelenturf of Cimetrics, Xiaohui Zhou of the Iowa Energy Center, Mike Macklin of the Des Moines Area Community College, and Joel Bender, H. Michael Newman, and Elaine Stanton-Hicks of Cornell University. 


\section{Table of Contents}

Results from Field Testing of Air Handling Unit and Variable Air Volume Box Fault Detection Tools

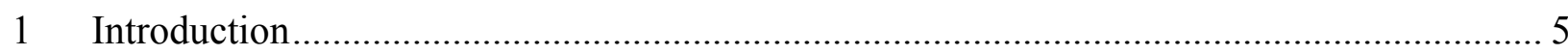

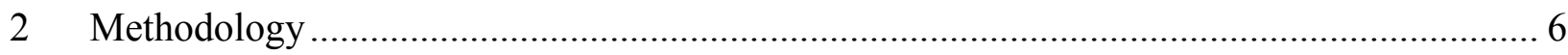

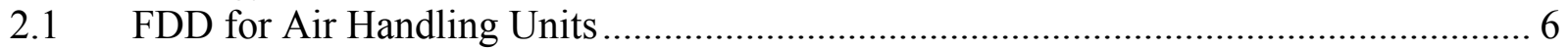

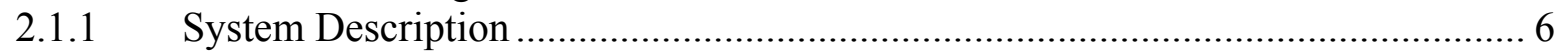

2.1.2 AHU Performance Assessment Rules (APAR) ............................................. 7

2.1.3 Instrumentation Accuracy Requirements ......................................................... 12

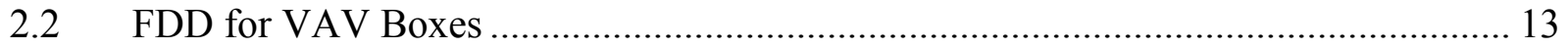

2.2.1 VAV box Performance Assessment Control Charts - VPACC ............................. 13

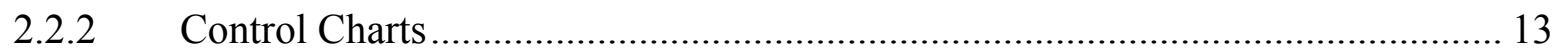

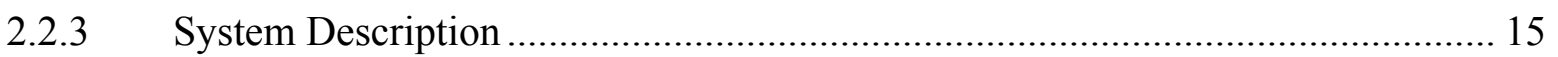

2.2.4 CUSUM Applied to VAV Box Diagnostics …………….................................. 16

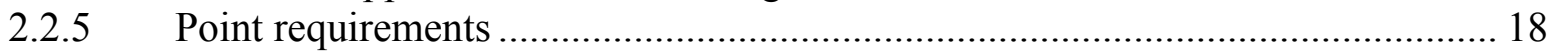

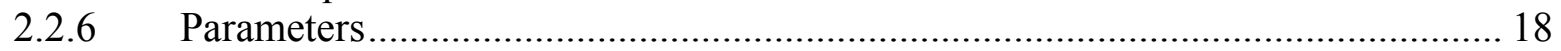

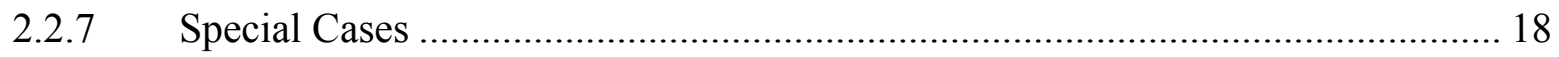

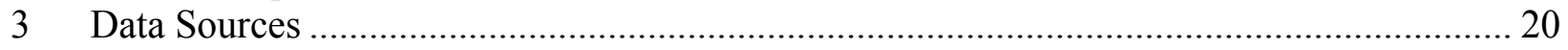

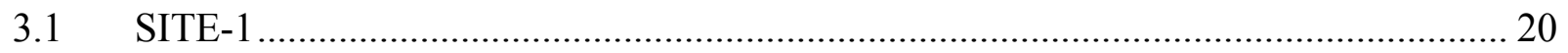

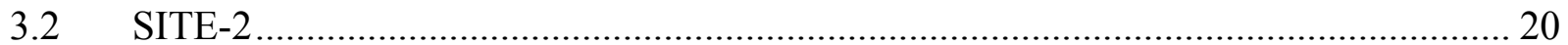

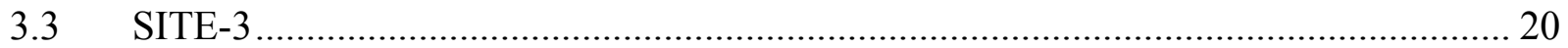

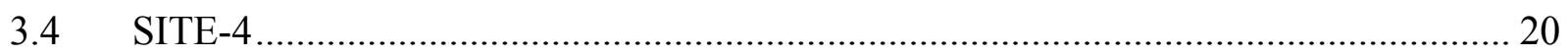

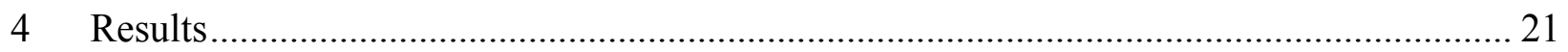

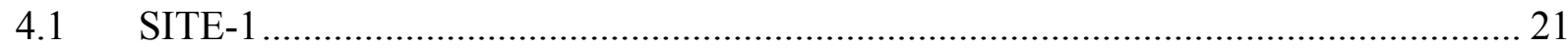

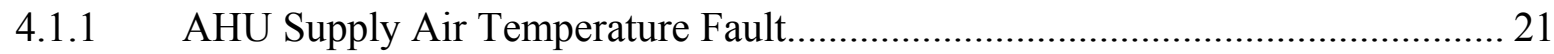

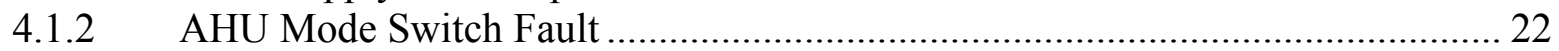

4.1.3 AHU Simultaneous Heating and Cooling Fault................................................ 22

4.1.4 AHU Temperature Sensor / Damper Fault .......................................................... 23

4.1.5 VAV Box Zone Temperature Fault ………...................................................... 24

4.2 SITE-2

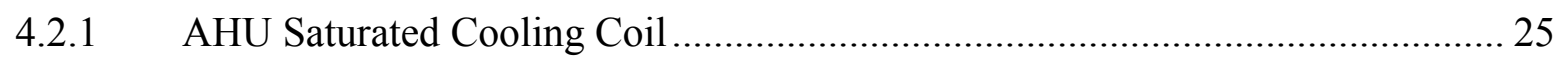

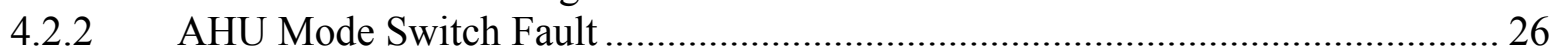

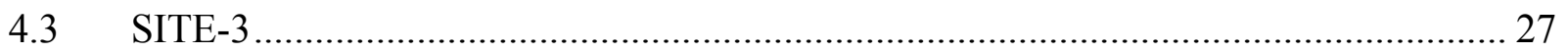

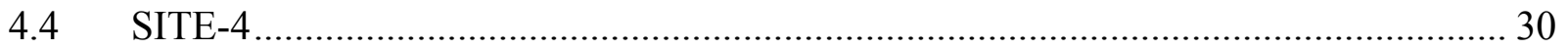

4.4.1 AHU Simultaneous Heating and Cooling Fault..................................................... 30

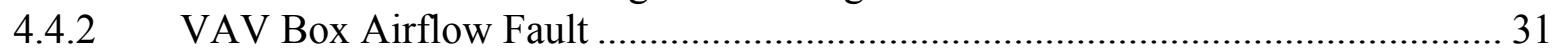

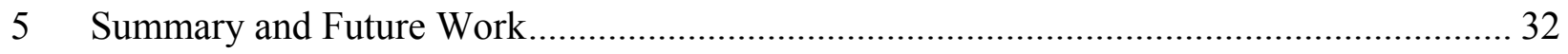

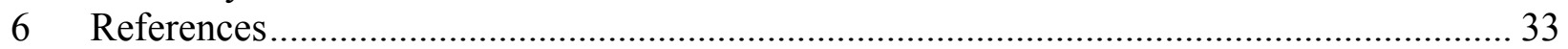




\section{Introduction}

Building HVAC equipment routinely fails to satisfy performance expectations envisioned at design. Such failures often go unnoticed for extended periods of time. Additionally, higher expectations are being placed on a combination of different and often conflicting performance measures, such as energy efficiency, indoor air quality, comfort, reliability, limiting peak demand on utilities, etc. To meet these expectations, the processes, systems, and equipment used in both commercial and residential buildings are becoming increasingly sophisticated. This development both necessitates the use of automated diagnostics to ensure fault-free operation and enables diagnostic capabilities for the various building systems by providing a distributed platform that is powerful and flexible enough to perform fault detection and diagnostics (FDD).

The purpose of the research effort described in this report is to develop, test, and demonstrate FDD methods that can detect common mechanical faults and control errors in air-handling units (AHUs) and variable-air-volume (VAV) boxes. The tools are intended to be sufficiently simple that they can be embedded in commercial building control systems and rely upon only sensor data and control signals that are commonly available in commercial building automation and control systems.

AHU Performance Assessment Rules (APAR) is a diagnostic tool that uses a set of expert rules derived from mass and energy balances to detect common faults in air-handling units. Control signals are used to determine the mode of operation for the AHU. A subset of the expert rules corresponding to that mode of operation is then evaluated to determine if there is a mechanical fault or a control problem. VAV box Performance Assessment Control Charts (VPACC) is a diagnostic tool that uses statistical quality control measures to detect faults or control problems in VAV boxes. VPACC can be applied to most VAV box control strategies. Fault thresholds are determined by statistical analysis of a database of "normal operation" data. The FDD tools for AHUs and VAV boxes are being developed with distinct approaches because of the nature of the systems. VAV boxes are simple devices with a limited number of operation modes and possible faults. Because the building industry is sensitive to first cost, the VAV boxes typically have little instrumentation and controllers with limited capability. However, VAV boxes are very numerous in a typical HVAC system, resulting in a large amount of data to be monitored for faults. AHUs are more complex and thus susceptible to more kinds of faults. They also tend to have more instrumentation and more capable controllers. The FDD tools for both systems are designed to be robust so that they can adapt to the variety of applications typical of their use.

A previous study [1], describes the theoretical basis of APAR and VPACC and evaluates the tools' performance using data generated by simulation, emulation, and laboratory testing. The study examined the breadth of faults that can be detected and the conditions under which they can be detected. This report describes the results of a research study to extend the previous work by evaluating the application of APAR and VPACC to HVAC systems in real buildings. The research, involving the collection of AHU and VAV box data from several field sites, examined the effectiveness of these tools in detecting 
commonly found mechanical faults and control problems, the reliability of the tools across several seasons, and the robustness of the tools in handling data from a variety of system types and configurations. The sites include an office building, a restaurant, as well as community college and university campuses, featuring constant- and variable-airvolume systems.

\section{Methodology}

\subsection{FDD for Air Handling Units}

The fault detection tool described in this section was developed for application to single duct variable-volume or constant-volume air handlers with hydronic heating and cooling coils and airside economizers. The rules that are used for FDD focus on temperature control in an AHU. Hence, the system description will be restricted to components and control strategies directly related to temperature control. Figure 2.1 is a schematic diagram of a typical single duct air handling unit (AHU).

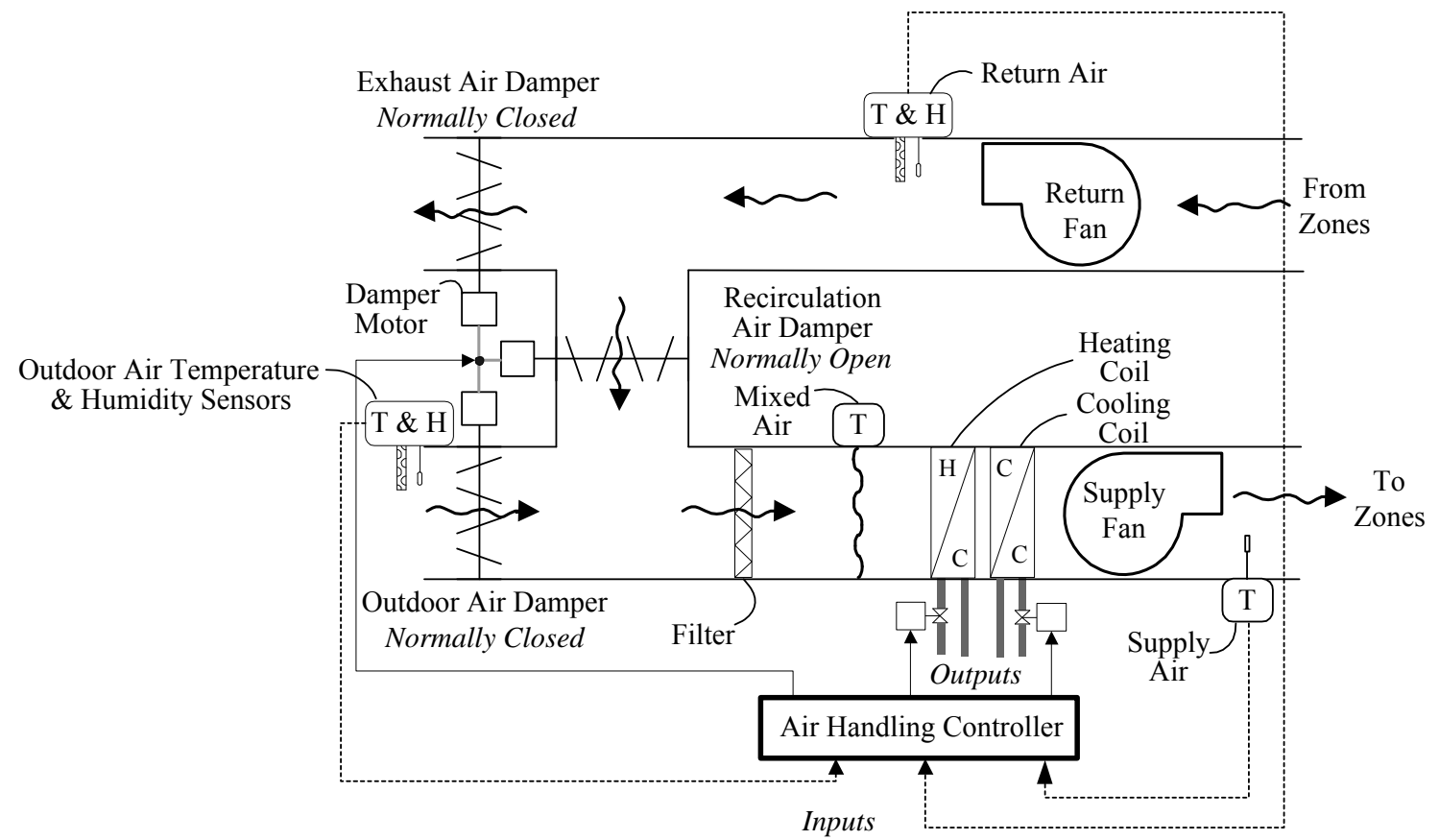

Figure 2.1: Schematic diagram of a single duct air-handling unit

\subsubsection{System Description}

The AHU controller typically controls the supply air temperature to maintain a setpoint temperature at a location in the supply duct downstream of the supply fan. Outdoor air enters the AHU and is mixed with air returned from the building. The mixed air passes over the heating and cooling coils, where if necessary, it is conditioned prior to being supplied to the building. The typical operating sequence for AHUs consists of four primary modes of operation during occupied periods for maintaining the supply air 
temperature and the ventilation at preset levels. The relationship of the four operating modes to the control of the heating coil valve, the cooling coil valve and the mixing box dampers is shown in Figure 2.2. Sequencing logic determines the mode of operation as dictated by various thermal relationships including the internal and external loads on the zones served by the AHU.

In the heating mode (Mode 1 in Figure 2.2), the heating coil valve is controlled to maintain the supply air temperature at the heating set point and the cooling coil valve is closed. The mixed air dampers are positioned to allow the minimum outdoor air necessary to satisfy ventilation requirements.

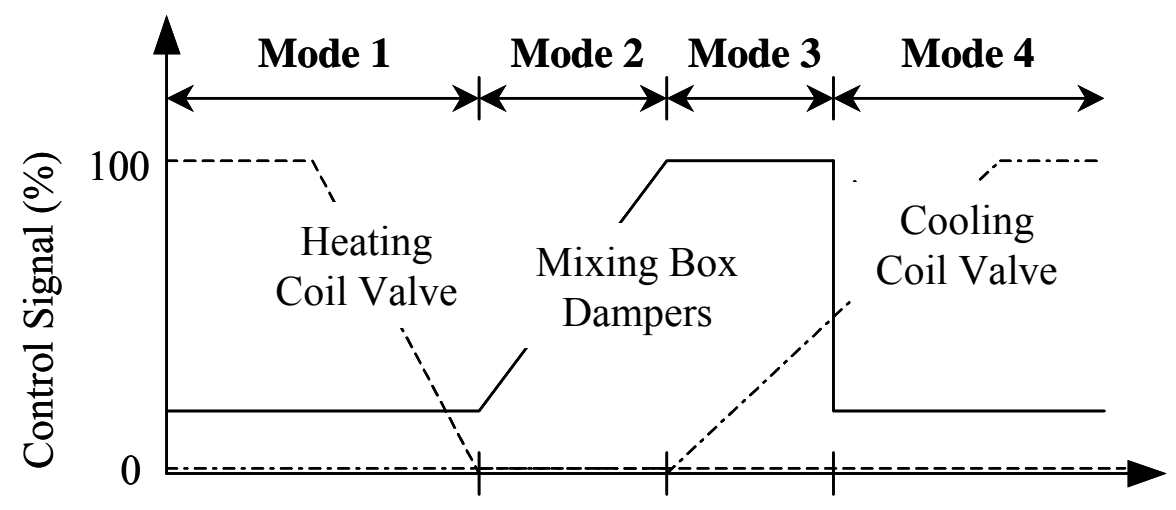

Figure 2.2: Typical operating modes of an air-handling unit

As cooling loads increase, the AHU transitions from heating to cooling with outside air (Mode 2). In this mode, the heating and cooling coil valves are closed and the mixing box dampers are modulated to maintain the supply air temperature at cooling set point. As the loads continue to increase, the mixing dampers eventually saturate with the outdoor air damper fully open and the AHU changes over to mechanical cooling. When the AHU is operating in one of the mechanical cooling modes (Modes 3 and 4), the cooling coil valve modulates to maintain the supply air temperature at cooling set point, the heating coil valve is closed, and the outdoor air damper is either fully open or at its minimum position. There are several different types of economizer controls, generally the economizer control logic uses a comparison of the outdoor and return air temperatures or enthalpies to determine the proper position of the outdoor air damper such that mechanical cooling requirements are minimized. Hence, the third primary mode (Mode 3 ) of operation is mechanical cooling with $100 \%$ outdoor air and the fourth primary mode (Mode 4) of operation is mechanical cooling with minimum outdoor air.

\subsubsection{AHU Performance Assessment Rules (APAR)}

The basis for the fault detection methodology is a set of expert rules used to assess the performance of the AHU. The tool developed from these rules is referred to as APAR (AHU Performance Assessment Rules). APAR uses control signals and occupancy information to identify the mode of operation of the AHU, thereby identifying a subset of the rules that specify temperature relationships that are applicable for that mode. The two main mode classifications are occupied and unoccupied. For occupied periods, the mode is further categorized as described in the previous paragraph. For convenience, the 
operating modes are summarized below:

- Mode 1: heating

- Mode 2: cooling with outdoor air

- Mode 3: mechanical cooling with $100 \%$ outdoor air

- Mode 4: mechanical cooling with minimum outdoor air

- Mode 5: unknown

Because the direct digital control (DDC) output to the actuators of the heating and cooling coil valves and the mixing box dampers are known, the mode of operation can be ascertained. Although not depicted in Figure 2.2, a fifth mode of operation referred to "unknown" operation has been defined and listed above. The unknown mode applies to the case in which the AHU is running in an occupied mode, but none of the control output relationships defined for Modes 1-4 are satisfied. The unknown mode could be associated with mode transitions and/or with faulty operation such as simultaneous heating and cooling.

Once the mode of operation has been established, rules based on conservation of mass and energy can be used along with the sensor information that is typically available for controlling the AHUs. For example, normal operation in the mechanical cooling mode with $100 \%$ outdoor air (Mode 3) dictates that the outdoor and mixed air temperatures must be approximately equal. Defining $T_{o a}$ and $T_{m a}$ as the outdoor air and mixed air temperatures, respectively, the rule (defined as Rule 10) is written as

$$
\text { Rule 10: }\left|T_{o a}-T_{m a}\right|>\varepsilon_{t}
$$

where $\varepsilon_{t}$ is a threshold that depends on the uncertainty (or accuracy) of the measurements. The rules are written such that a fault is indicated if a rule is true. In the example above, the rule states that if the outdoor and mixed air temperatures are not the same (i.e., if true) a fault has occurred.

As a detailed description of the 28 APAR rules and the reasoning behind them is available elsewhere [2], the rules are simply listed in Table 2.1 without detailed explanation. Table 2.1 groups the rules according to mode of operation. As indicated in the column heading for the rule expression, a true expression indicates a fault. Table 2.2 presents the rules as related groups and indicates the sensors and control signals used to evaluate each rule. The first group of rules treats the relationship of temperatures in the coil subsystem of the AHU. For these four rules, only the relational operator in the rules change from one mode to another. A typical rule from this subgroup requires the supply air temperature to be lower than the sum of the mixed air temperature and the temperature rise across the supply fan in the mechanical cooling modes. There are also groups of rules treating the mixing box subsystem, the zone subsystem, economizer operation, comfort requirements, and controller logic/tuning. Hence, although there are 28 rules, in reality only a small number of temperature and control signal relationships are used to define the rules. 
Table 2.1: APAR Rule Set

\begin{tabular}{|c|c|c|}
\hline Mode & Rule \# & Rule Expression (true implies existence of a fault) \\
\hline \multirow{4}{*}{$\begin{array}{l}\text { Heating } \\
\text { (Mode 1) }\end{array}$} & 1 & $T_{s a}<T_{m a}+\Delta T_{s f}-\varepsilon_{t}$ \\
\hline & 2 & For $\left|T_{r a}-T_{o a}\right| \geq \Delta T_{\min }:\left|Q_{o a} / Q_{s a}-\left(Q_{o a} / Q_{s a}\right)_{\min }\right|>\varepsilon_{f}$ \\
\hline & 3 & $\left|u_{h c}-1\right| \leq \varepsilon_{h c} \quad$ and $\quad T_{s a, s}-T_{s a} \geq \varepsilon_{t}$ \\
\hline & 4 & $\left|u_{h c}-1\right| \leq \varepsilon_{h c}$ \\
\hline \multirow{3}{*}{$\begin{array}{l}\text { Cooling with } \\
\text { Outdoor Air } \\
\text { (Mode 2) }\end{array}$} & 5 & $T_{o a}>T_{s a, s}-\Delta T_{s f}+\varepsilon_{t}$ \\
\hline & 6 & $T_{s a}>T_{r a}-\Delta T_{r f}+\varepsilon_{t}$ \\
\hline & 7 & $\left|T_{s a}-\Delta T_{s f}-T_{m a}\right|>\varepsilon_{t}$ \\
\hline \multirow{7}{*}{$\begin{array}{l}\text { Mechanical } \\
\text { Cooling with } \\
\text { 100\% Outdoor } \\
\text { Air } \\
\text { (Mode 3) }\end{array}$} & 8 & $T_{o a}<T_{s a, s}-\Delta T_{s f}-\varepsilon_{t}$ \\
\hline & 9 & $T_{o a}>T_{c o}+\varepsilon_{t}$ \\
\hline & 10 & $\left|T_{o a}-T_{m a}\right|>\varepsilon_{t}$ \\
\hline & 11 & $T_{s a}>T_{m a}+\Delta T_{s f}+\varepsilon_{t}$ \\
\hline & 12 & $T_{s a}>T_{r a}-\Delta T_{r f}+\varepsilon_{t}$ \\
\hline & 13 & $\left|u_{c C}-1\right| \leq \varepsilon_{C C} \quad$ and $\quad T_{s a}-T_{s a, s} \geq \varepsilon_{t}$ \\
\hline & 14 & $\left|u_{C C}-1\right| \leq \varepsilon_{C C}$ \\
\hline \multirow{6}{*}{$\begin{array}{l}\text { Mechanical } \\
\text { Cooling with } \\
\text { Minimum } \\
\text { Outdoor Air } \\
\text { (Mode 4) }\end{array}$} & 15 & $T_{O a}<T_{C O}-\varepsilon_{t}$ \\
\hline & 16 & $T_{s a}>T_{m a}+\Delta T_{s f}+\varepsilon_{t}$ \\
\hline & 17 & $T_{s a}>T_{r a}-\Delta T_{r f}+\varepsilon_{t}$ \\
\hline & 18 & For $\left|T_{r a}-T_{o a}\right| \geq \Delta T_{\min }:\left|Q_{o a} / Q_{s a}-\left(Q_{o a} / Q_{s a}\right)_{\min }\right|>\varepsilon_{f}$ \\
\hline & 19 & $\left|u_{C C}-1\right| \leq \varepsilon_{c C} \quad$ and $\quad T_{s a}-T_{s a, s} \geq \varepsilon_{t}$ \\
\hline & 20 & $\left|u_{C C}-1\right| \leq \varepsilon_{C C}$ \\
\hline \multirow{4}{*}{$\begin{array}{l}\text { Unknown } \\
\text { Occupied } \\
\text { Modes } \\
\text { (Mode 5) }\end{array}$} & 21 & $u_{C C}>\varepsilon_{C C}$ and $u_{h c}>\varepsilon_{h c}$ and $\varepsilon_{d}<u_{d}<1-\varepsilon_{d}$ \\
\hline & 22 & $u_{h c}>\varepsilon_{h c}$ and $u_{C C}>\varepsilon_{C C}$ \\
\hline & 23 & $u_{h c}>\varepsilon_{h c}$ and $u_{d}>\varepsilon_{d}$ \\
\hline & 24 & $\varepsilon_{d}<u_{d}<1-\varepsilon_{d}$ and $u_{C C}>\varepsilon_{C C}$ \\
\hline \multirow{4}{*}{$\begin{array}{l}\text { All Occupied } \\
\text { Modes } \\
\text { (Mode 1, 2, 3, 4, } \\
\text { or 5) }\end{array}$} & 25 & $\left|T_{s a}-T_{s a, s}\right|>\varepsilon_{t}$ \\
\hline & 26 & $T_{m a}<\min \left(T_{r a}, T_{o a}\right)-\varepsilon_{t}$ \\
\hline & 27 & $T_{m a}>\max \left(T_{r a}, T_{o a}\right)+\varepsilon_{t}$ \\
\hline & 28 & Number of mode transitions per hour $>M T_{\max }$ \\
\hline
\end{tabular}




\begin{tabular}{|c|c|c|}
\hline Vhere & & \\
\hline$M T_{\max }$ & $=$ & maximum number of mode changes per hour \\
\hline$T_{\text {sa }}$ & $=$ & supply air temperature \\
\hline$T_{m a}$ & $=$ & mixed air temperature \\
\hline$T_{r a}$ & $=$ & return air temperature \\
\hline$T_{\text {oa }}$ & $=$ & outdoor air temperature \\
\hline$T_{C O}$ & $=$ & changeover air temperature for switching between Modes 3 and 4 \\
\hline$T_{\text {Sa,s }}$ & $=$ & supply air temperature set point \\
\hline$\Delta T_{s f}$ & $=$ & temperature rise across the supply fan \\
\hline$\Delta T_{r f}$ & $=$ & temperature rise across the return fan \\
\hline$\Delta T_{\min }$ & & $\begin{array}{l}\text { threshold on the minimum temperature difference between the } \\
\text { return and outdoor air }\end{array}$ \\
\hline$Q_{o a} / Q_{s a}$ & $=$ & outdoor air fraction $=\left(T_{m a}-T_{r a}\right) /\left(T_{o a}-T_{r a}\right)$ \\
\hline$\left(Q_{o a} / Q_{s a}\right)_{\min }$ & $=$ & threshold on the minimum outdoor air fraction \\
\hline$u_{h c}$ & $=$ & $\begin{array}{l}\text { normalized heating coil valve control signal }[0,1] \text { where } u_{h c}=0 \\
\text { indicates the valve is closed and } u_{h c}=1 \text { indicates it is } 100 \% \text { open }\end{array}$ \\
\hline$u_{C C}$ & $=$ & $\begin{array}{l}\text { normalized cooling coil valve control signal }[0,1] \text { where } u_{C C}=0 \\
\text { indicates the valve is closed and } u_{C C}=1 \text { indicates it is } 100 \% \text { open }\end{array}$ \\
\hline$u_{d}$ & $=$ & $\begin{array}{l}\text { normalized mixing box damper control signal }[0,1] \text { where } u_{d}=0 \\
\text { indicates the outdoor air damper is closed and } u_{d}=1 \text { indicates it is } \\
100 \% \text { open }\end{array}$ \\
\hline$\varepsilon_{t}$ & $=$ & threshold for errors in temperature measurements \\
\hline$\varepsilon_{f}$ & & $\begin{array}{l}\text { threshold parameter accounting for errors related to airflows } \\
\text { (function of uncertainties in temperature measurements) }\end{array}$ \\
\hline$\varepsilon_{h c}$ & $=$ & threshold parameter for the heating coil valve control signal \\
\hline$\varepsilon_{C C}$ & $=$ & threshold parameter for the cooling coil valve control signal \\
\hline$\varepsilon_{d}$ & $=$ & threshold parameter for the mixing box damper control signal \\
\hline
\end{tabular}

\subsubsection{Operational and Design Data Requirements}

APAR uses the following occupancy information, setpoint values, sensor measurements, and control signals:

- Occupancy status;

- Supply air temperature set point;

- Supply air temperature;

- Return air temperature;

- Mixed air temperature;

- Outdoor air temperature;

- Cooling coil valve control signal;

- Heating coil valve control signal;
- Mixing box damper control signal;

- Return air relative humidity (for enthalpy-based economizers only)

- Outdoor air relative humidity (for enthalpy-based economizers only). 
Table 2.2: Summary of Rule Relationships

\begin{tabular}{|c|c|c|c|c|c|c|c|c|c|c|c|c|c|}
\hline \multirow{2}{*}{ Rule } & \multirow{2}{*}{ Mode * } & \multicolumn{11}{|c|}{ Sensors and Control Signals } & \multirow{2}{*}{ Relationship Between Grouped Rules } \\
\hline & & $\mathrm{T}_{\mathrm{sa}}$ & $\mathrm{T}_{\mathrm{ra}}$ & $\mathrm{T}_{\mathrm{ma}}$ & $\mathrm{T}_{\mathrm{oa}}$ & $\mathrm{T}_{\mathrm{sa}, \mathrm{s}}$ & $\Delta \mathrm{T}_{\mathrm{sf}}$ & $\Delta \mathrm{T}_{\text {rf }}$ & $\mathrm{T}_{\mathrm{co}}$ & $\mathrm{u}_{\mathrm{cc}}$ & $u_{h c}$ & $\mathrm{u}_{\mathrm{d}}$ & \\
\hline 1 & 1 & 囯 & & 圆 & & & 圆 & & & & & & \multirow{4}{*}{$\begin{array}{l}\text { Coil Subsystem: The relational sign }(<,>, \text { etc. }) \\
\text { changes based on the mode of operation. }\end{array}$} \\
\hline 7 & 2 & 吐 & & 氤 & & & 囯 & & & & & & \\
\hline 11 & 3 & 固 & & 宔 & & & 固 & & & & & & \\
\hline 16 & 4 & 国 & & 高 & & & 固 & & & & & & \\
\hline 2 & 1 & & 固 & 固 & 国 & & & & & & & & \multirow{4}{*}{$\begin{array}{l}\text { Mixing Box Subsystem: Rules are related } \\
\text { through calculation of outdoor air fraction. If } \\
\text { Rule } 26 \text { or } 27 \text { is satisfied, the outdoor air } \\
\text { fraction will be negative or greater than unity. }\end{array}$} \\
\hline 18 & 4 & & 国 & 囯 & 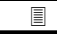 & & & & & & & & \\
\hline 26 & $1,2,3,4$ & & 圆 & 囯 & 固 & & & & & & & & \\
\hline 27 & $1,2,3,4$ & & 固 & 国 & 固 & & & & & & & & \\
\hline 25 & $1,2,3,4$ & 固 & & & & 国 & & & & & & & \multirow{7}{*}{$\begin{array}{l}\text { Comfort Requirements: The first four rules } \\
\text { indicate comfort is sacrificed (with Rules } 3,13 \text {, } \\
\text { and } 19 \text { indicating the system is out of control), } \\
\text { whereas the latter three rules indicate comfort } \\
\text { could soon be sacrificed (system is out of } \\
\text { control). }\end{array}$} \\
\hline 3 & 1 & 吐 & & & & 吐 & & & & & 夙 & & \\
\hline 13 & 3 & 囯 & & & & 固 & & & & 固 & & & \\
\hline 19 & 4 & 固 & & & & 国 & & & & 固 & & & \\
\hline 4 & 1 & & & & & & & & & & 固 & & \\
\hline 14 & 3 & & & & & & & & & 固 & & & \\
\hline 20 & 4 & & & & & & & & & 固 & & & \\
\hline 5 & 2 & & & & 国 & 国 & 固 & & & & & & \multirow{2}{*}{$\begin{array}{l}\text { The relational sign }(<,>\text {, etc.) changes based } \\
\text { on the mode of operation. }\end{array}$} \\
\hline 8 & 3 & & & & 固 & 国 & 固 & & & & & & \\
\hline 6 & 2 & 固 & 固 & & & & & 固 & & & & & \multirow{3}{*}{ Zone Subsystem: Rules are identical. } \\
\hline 12 & 3 & 固 & 固 & & & & & 畐 & & & & & \\
\hline 17 & 4 & 固 & 聵 & & & & & 固 & & & & & \\
\hline 9 & 3 & & & & 固 & & & & 固 & & & & \multirow{2}{*}{$\begin{array}{l}\text { Economizer: The relational sign ( }<,>\text {, etc.) } \\
\text { changes based on the mode of operation. }\end{array}$} \\
\hline 15 & 4 & & & & 国 & & & & 固 & & & & \\
\hline 10 & 3 & & & 固 & 国 & & & & & & & & \\
\hline 21 & - & & & & & & & & & 固 & 固 & 固 & \multirow{5}{*}{$\begin{array}{l}\text { Controller Logic/Tuning: Rules are related and } \\
\text { identify periods of operation associated with } \\
\text { controller problems, such as simultaneous } \\
\text { heating and cooling, and excessive mode } \\
\text { changes. }\end{array}$} \\
\hline 22 & - & & & & & & & & & 固 & 固 & & \\
\hline 23 & - & & & & & & & & & & 固 & 国 & \\
\hline 24 & - & & & & & & & & & 固 & & 固 & \\
\hline 28 & - & & & & & & & & & 固 & 罣 & 囯 & \\
\hline
\end{tabular}

* The dash symbol indicates either an unknown mode or multiple modes of operation.

With the possible exception of the mixed air temperature, this information is generally available for most AHUs controlled with a DDC system. If one or more sensors are not available, certain rules will no longer be applicable. For instance, in the absence of a mixed air temperature sensor, nine rules listed in Table 2.1 (Rules 1, 2, 7, 10, 11, 16, 18, 26, and 27) will be eliminated from consideration in APAR. Conversely, the presence of additional sensors would expand the rule set and provide an opportunity to either detect more faults, or to detect faults during modes of operation in which they would normally be hidden. For instance, if a temperature sensor was installed between the heating and cooling coils, leakage through the heating valve could be detected during the mechanical cooling modes, whereas normally it would be masked in these modes.

In addition to the operational data listed above, certain design data are needed to implement the rules. The required design data are:

- Minimum and maximum values of control signals for the heating coil valve, cooling coil valve and mixing box dampers for normalizing the control signals;

- Percentage outdoor air necessary to satisfy ventilation requirements;

- Changeover temperature from mechanical cooling with $100 \%$ outdoor air to mechanical cooling with minimum outdoor air (or equivalent condition for enthalpy-based economizer);

- Description of sequencing/economizer cycle strategy (used to verify that the rules are suitable to a particular AHU installation). 


\subsubsection{Detecting and Diagnosing Faults}

APAR does not search for the existence of a specific set of faults. Rather, any fault that causes a rule to be satisfied would be detected and additional effort would be necessary to isolate the source of the problem. Emulation, simulation, and laboratory experimentation from previous work [1] as well as the current study demonstrate that the rule set can identify the following faults:

- Stuck or leaking mixing box dampers, heating coil valves, and cooling coil valves;

- Temperature sensor faults;

- Design faults such as undersized coils;

- Controller programming errors related to tuning, setpoints, and sequencing logic;

- Inappropriate operator intervention.

The operating point, severity of a fault, and threshold selection for the rules will obviously influence when a particular rule is satisfied. Threshold selection is discussed next.

\subsubsection{Threshold Selection}

In addition to the sensor, control signals, and setpoint information, there are other parameters that must be specified for APAR. For instance, estimates of the temperature rise across the supply fan (and return fan, if one exists) must be provided, a reasonable default is $1.1{ }^{\circ} \mathrm{C}\left(2.0^{\circ} \mathrm{F}\right)$. A model-based value correlated to the airflow rate or the control signal to the fan could be used as the basis for this estimate; however, some amount of training data would likely be necessary to establish the correlation. Thresholds used in evaluation of rules such as $\varepsilon_{t}$ in Rule 10 must also be specified. Another approach might be to calculate the threshold values based on the uncertainty of each sensor or actuator value. As an example, the threshold in Rule 10 would be determined from the expression

$$
\varepsilon_{t}=\varepsilon_{T_{o a}}+\varepsilon_{T_{m a}}
$$

where $\varepsilon_{T_{o a}}$ and $\varepsilon_{T_{m a}}$ are the uncertainties associated with the measurement of the outdoor and mixed air temperatures. If a threshold is too great, the associated fault(s) must be relatively severe to be detected. If, on the other hand, a threshold is too small, normal variation in operating conditions may result in false alarms. These threshold values are currently determined heuristically for each site.

\subsubsection{Instrumentation Accuracy Requirements}

APAR uses existing sensor points in the control system to perform the fault detection calculations. The typical industrial grade sensors that are already installed for control purposes have sufficient accuracy. Laboratory grade instruments are not required. Higher quality sensors that have been installed and calibrated properly will allow the use of tighter thresholds (less severe faults can be detected) than lower quality sensors, or those that have been poorly calibrated or installed. 


\subsection{FDD for VAV Boxes}

\subsubsection{VAV box Performance Assessment Control Charts - VPACC}

The primary purpose of heating, ventilating, and air-conditioning (HVAC) equipment in commercial buildings is to provide a comfortable and healthy environment for occupants. Variable-air-volume (VAV) air handling systems are common for conditioning air and delivering the air to occupied zones. VAV boxes are an integral part of such systems and are the final piece of equipment that air passes through prior to reaching the occupants. As such, it is important to ensure that these devices operate correctly.

The challenges presented in detecting and diagnosing faults in VAV boxes are similar to those encountered with other pieces of HVAC equipment. Generally there are very few sensors, making it difficult to ascertain what is happening in the device. Limitations associated with controller memory and communication capabilities further complicate the task. The number of different types of VAV boxes and lack of standardized control sequences add a final level of complexity to the challenge. This set of constraints is counterbalanced by the fact that VAV boxes are much more numerous than other pieces of HVAC equipment. For instance, buildings may have ten to fifteen times more VAV boxes than air-handling units. Hence, maintenance staffs would clearly benefit from a tool that assisted them in monitoring VAV box operation.

The needs and constraints described above have led to the development of VAV Box Performance Assessment Control Charts (VPACC), a fault detection tool that uses a small number of control charts to assess the performance of VAV boxes. The underlying approach, while developed for a specific type of VAV box and control sequence, is general in nature and can be adapted to other types of VAV boxes. This section describes the basic concept of control charts and their use for determining when control processes have gone "out of control". The specific control charts developed and implemented in VPACC are then presented for a single duct pressure-independent throttling VAV box with reheat.

\subsubsection{Control Charts}

Control charts are common tools for monitoring control processes wherein a measured quantity is compared to upper and lower limits that define allowable (or fault free) operation. If the measured quantity falls outside these limits, the process is said to be "out of control." The limits are typically defined using statistical parameters and, therefore, control charts are often referred to as statistical quality control charts.

There are many different types of control charts. VPACC implements an algorithm known as a CUSUM (cumulative sum) chart. The basic concept behind CUSUM charts is to accumulate the error between a process output and the expected value of the output. Large values of the accumulated error are indicative of an out of control process. With the process output at sampling time $\mathrm{i}$ denoted $\mathrm{x}_{\mathrm{i}}$, the estimate of the expected value denoted $\hat{\mathrm{x}}$, and the estimate of the process standard deviation denoted by $\hat{\sigma}$, the normalized process output is given by: 


$$
\mathrm{z}_{\mathrm{i}}=\frac{\mathrm{x}_{\mathrm{i}}-\hat{\mathrm{x}}}{\hat{\sigma}}
$$

The normalized process output is used to compute two cumulative sums defined as follows:

$$
\begin{aligned}
& \mathrm{S}_{\mathrm{i}}=\max \left[0, \mathrm{z}_{\mathrm{i}}-\mathrm{k}+\mathrm{S}_{\mathrm{i}-1}\right] \\
& \mathrm{T}_{\mathrm{i}}=\min \left[0, \mathrm{z}_{\mathrm{i}}+\mathrm{k}+\mathrm{T}_{\mathrm{i}-1}\right]
\end{aligned}
$$

where $\mathrm{k}$ is a slack parameter that must be specified. Positive values of $\mathrm{z}$ greater than $k$ cause the sum $S$ to move away from zero and the sum $T$ to approach or remain at zero. Negative values of $z$ less than $-k$ cause the sum $T$ to move away from zero and the sum $S$ to approach or remain at zero. A process is said to be out of control when either $S$ exceeds a threshold value defined by the parameter $h$, or $T$ falls below $-h$. Figure 2.3 [3] presents normalized data and the $\mathrm{S}$ and $\mathrm{T}$ cumulative sums for $\mathrm{k}=0.5$ and $\mathrm{h}=5$. The first 20 data points come from a random normal distribution with a mean value of zero and a standard deviation of unity. The mean value is then increased to $0.25,0.5,0.75$ and 1.0 for subsequent sets of 20 data points. Note that $\mathrm{S}$ exceeds the threshold value of $h$ after about 68 data points. Because the mean value increases above 0 , the cumulative sum $\mathrm{T}$ remains above its threshold of -5 .

CUSUM charts are generally considered to be effective for detecting gradual shifts in the process mean. The most commonly used control charts are Shewhart and Shewhart-type charts. Shewhart charts are effective for detecting large, sudden changes in the process mean. Generally Shewhart chart limits are set at values of $\hat{x} \pm 3 \hat{\sigma}$. In terms of the normalized parameter $z$, the chart limits are $z= \pm 3$. Shewhart charts were not investigated as part of this study; however, it is interesting to note that the basic CUSUM and Shewhart charts are equivalent if the CUSUM parameters $\mathrm{k}$ and $\mathrm{h}$ are selected as $\mathrm{k}=3$ and $\mathrm{h}=0$.
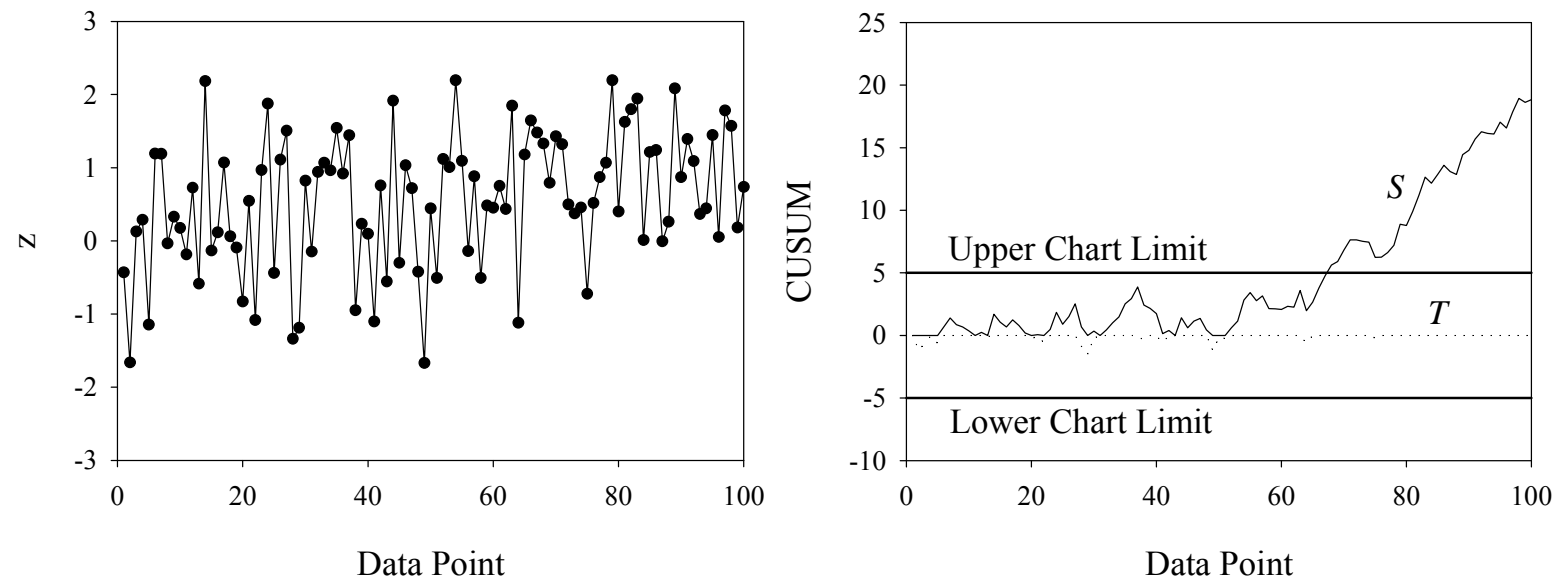

Figure 2.3: A simple CUSUM control chart indicating an “out of control” process. 


\subsubsection{System Description}

Figure 2.4 is a schematic diagram of a typical single duct variable-air-volume (VAV) box with hydronic reheat. The diagram depicts a damper that is used to modulate airflow to the zone and a control valve that modulates hot water flow to the reheat coil. Several sensors are also shown in

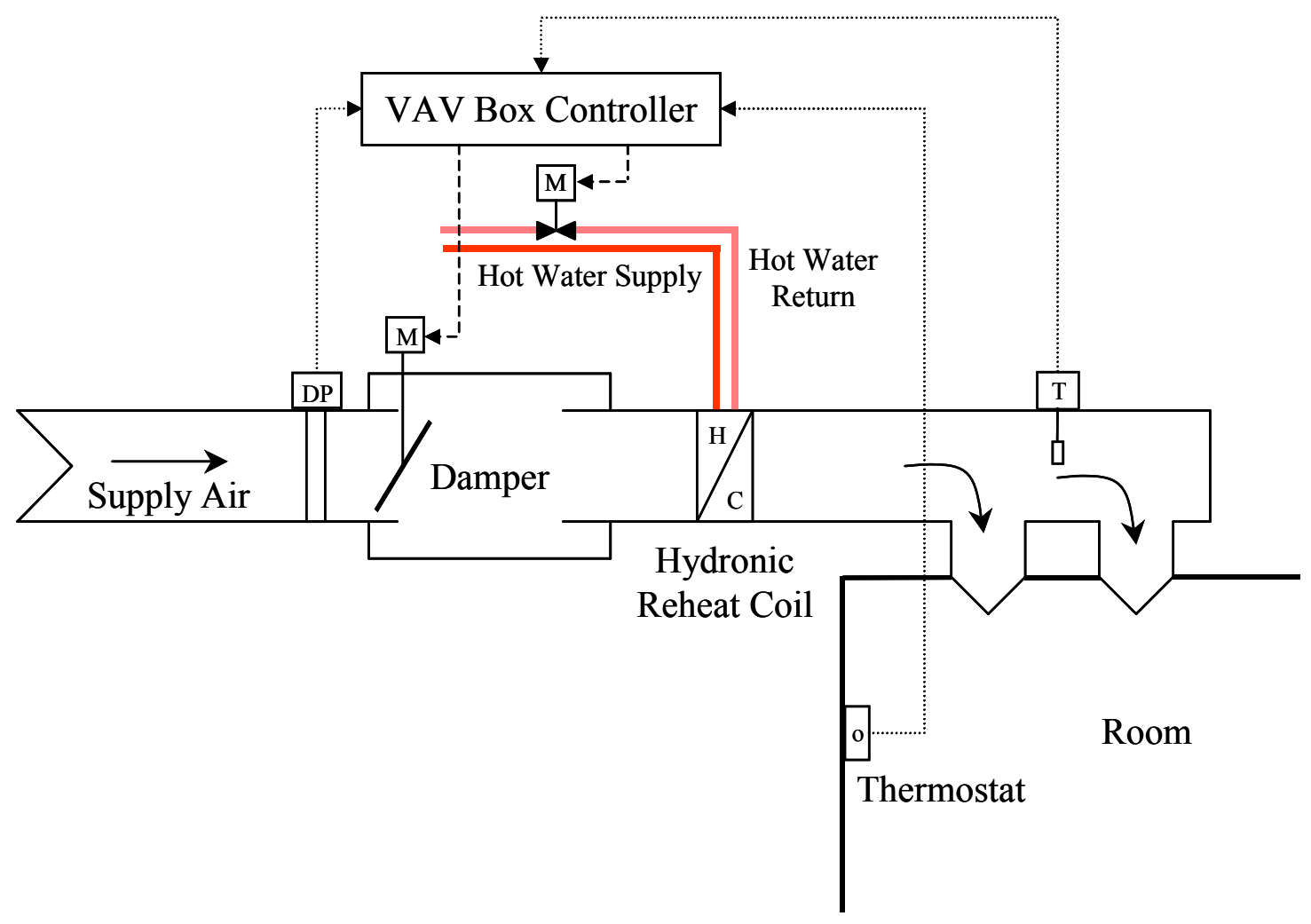

Figure 2.4: Schematic diagram of a single duct pressure-independent VAV box with hydronic reheat.

Figure 2.4. The zone thermostat measures the air temperature in the zone. The differential pressure transducer is used to measure the flow rate of air into the zone. Finally, the discharge air temperature sensor measures the temperature of the air stream entering the zone. This sensor is used to provide diagnostic information rather than for control purposes. The VAV box controller reads the sensor information, computes control outputs for the damper and reheat valve, and transmits these signals to the appropriate actuators.

Figure 2.5 shows a typical control sequence for a pressure-independent VAV box. A heating set point and a cooling set point are specified. As the zone temperature increases above the cooling set point, the airflow rate to the zone increases proportionally. This is accomplished by resetting the airflow rate setpoint and modulating the damper to achieve this airflow rate. As the zone temperature decreases toward the cooling set point, the airflow rate setpoint is decreased and the damper gradually closes until it is providing the minimum flow rate necessary for ventilation. If the room temperature continues to decrease and reaches the heating set point, the reheat valve will begin to open. The airflow rate can also be varied in the heating mode, with the airflow increasing as the temperature decreases. Alternatively, a higher fixed airflow rate may be specified for heating operation to improve the distribution of the warm air. In Figure 2.5, it is 
assumed that a fixed airflow rate associated with the ventilation requirement of the room is provided in the heating mode.

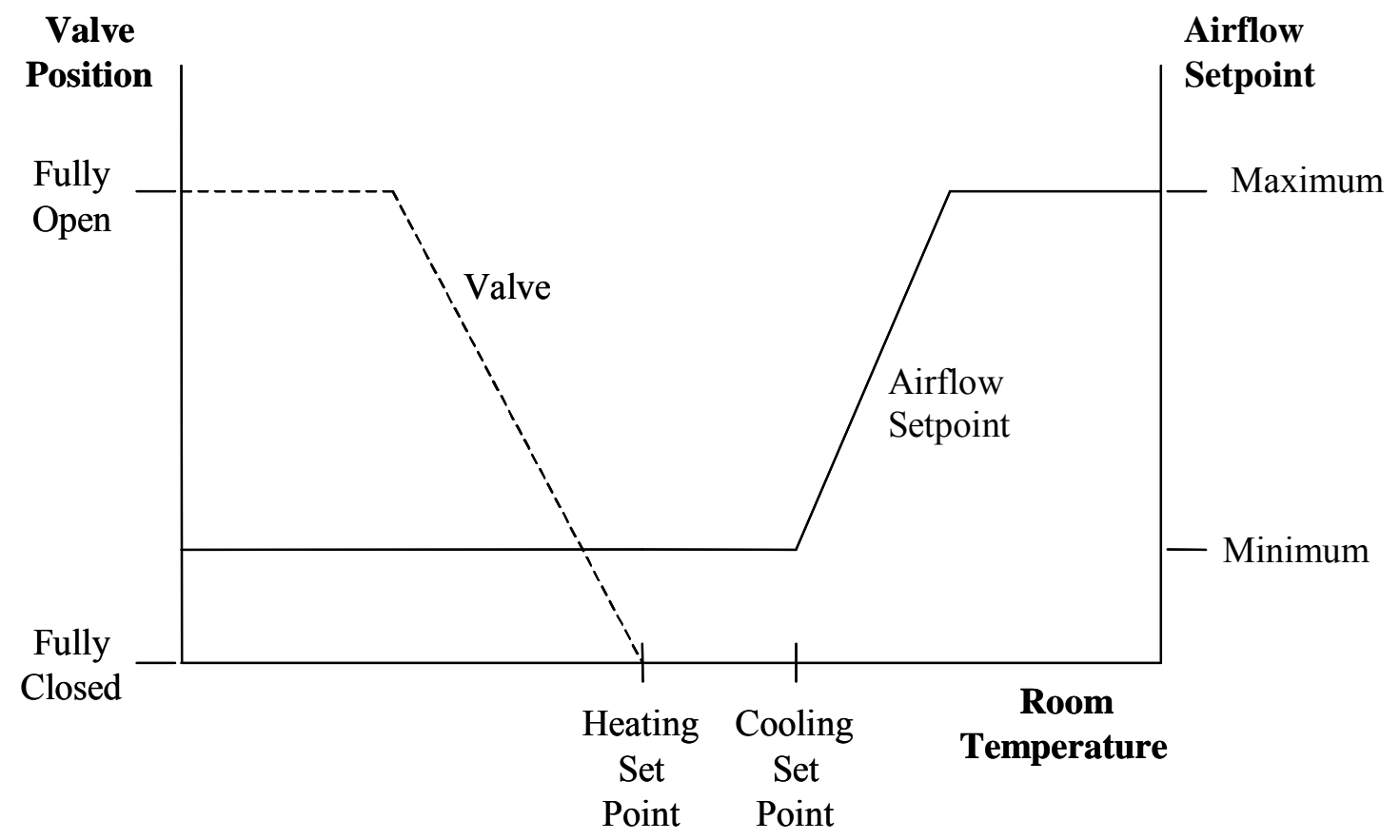

Figure 2.5: Damper and valve control sequence as a function of room temperature for a single duct pressure-independent VAV box with hydronic reheat.

\subsubsection{CUSUM Applied to VAV Box Diagnostics}

The previous section described one particular VAV box control strategy. However, a wide variety of control strategies are employed by controller manufacturers, most of which use a cascaded control loop to maintain the zone temperature and zone airflow rate at setpoint values. In order to make VPACC independent of the control strategy used in a particular controller/VAV box application, four generic errors were identified: the airflow rate error, the absolute value of the airflow rate error, the temperature error, and the reheat coil differential temperature error. As long as the VAV box controller has an airflow setpoint, as well as heating and cooling temperature setpoints, VPACC will function independently of the control strategy used. Common mechanical and control faults will result in a deviation of one or more of these errors from its value during normal operation, which can be detected by a CUSUM chart.

The airflow rate error, $Q_{e r r o r}$, is defined as

$$
Q_{\text {error }}=Q_{\text {actual }}-Q_{\text {setpoint }}
$$

where

$Q_{\text {actual }}=$ measured airflow rate

$Q_{\text {setpoint }}=$ airflow rate set point. 
The CUSUMs of this error, $S_{Q}$ and $T_{Q}$, are effective for detecting damper faults and differential pressure sensor faults associated with airflow measurement.

The absolute value of the airflow rate error, $\left|Q_{\text {error }}\right|$, is defined as

$$
\left|Q_{\text {error }}\right|=\left|Q_{\text {actual }}-Q_{\text {setpoint }}\right|
$$

Only one CUSUM value, $S_{|Q|}$, is defined for this error since the error is never negative. $S_{|Q|}$ is effective for detecting unstable damper control faults.

The temperature error, $T_{\text {error }}$, is defined as

$$
\begin{array}{ll}
T_{\text {error }}=T_{\text {zone }}-C S P & : \text { If } T_{\text {zone }}>C S P \\
T_{\text {error }}=0 & : \text { If } H S P \leq T_{\text {zone }} \leq C S P \\
T_{\text {error }}=T_{\text {zone }}-H S P & : \text { If } T_{\text {zone }}<H S P
\end{array}
$$

where

$$
\begin{aligned}
& T_{\text {zone }}=\text { zone temperature } \\
& \text { CSP }=\text { cooling set point } \\
& H S P=\text { heating set point }
\end{aligned}
$$

The CUSUMs of the temperature error, $S_{T}$ and $T_{T}$, are effective for detecting damper faults, valve faults, and temperature sensor faults. The specific definition of temperature error used in this report is based on the control sequence described above. Various other commonly used control sequences may require changes to the definitions of heating setpoint, cooling setpoint, and temperature error.

The reheat coil differential temperature error, $\Delta T_{\text {error }}$, is defined as

$$
\begin{array}{ll}
\Delta T_{\text {error }}=T_{\text {discharge }}-T_{\text {entering }} & : \text { If } u_{h c}=0 \\
\Delta T_{\text {error }}=0 & : \text { If } u_{h c} \neq 0
\end{array}
$$

where

$T_{\text {discharge }}=$ discharge air temperature (the temperature of the air leaving the reheat coil)

$T_{\text {entering }}=$ entering air temperature (the temperature of the air entering the reheat coil)

$u_{h c} \quad=$ control signal to the reheat coil valve.

The positive CUSUM of the reheat coil differential temperature error, $S_{\Delta T}$, is effective for detecting a leaking reheat coil valve fault. The negative CUSUM, $T_{\Delta T}$, is effective for detecting temperature sensor faults. The leaking valve fault highlights the advantages of automated FDD. Without VPACC, the local controller may be capable of masking this fault by increasing the airflow rate into the space. In this scenario there will be no "too hot" or "too cold" complaints, so a significant energy penalty may be accrued. 
The errors and CUSUMs are only calculated during occupied periods. During unoccupied periods, the errors are not computed, and the CUSUMs are reset to zero. The first hour of the occupied period is treated the same as the unoccupied period, to allow steady state conditions to develop.

\subsubsection{Point requirements}

Most of the points required by VPACC are already available in the local VAV box controller: room temperature, cooling setpoint, heating setpoint, airflow rate setpoint, actual airflow rate, and occupancy status. Entering air temperature is typically not available, so supply air temperature (available over the control network from the AHU controller) could be used. Many VAV boxes are equipped with a discharge air temperature sensor, which VPACC needs in order to calculate the reheat coil differential temperature error. If a discharge air temperature sensor is not available, a simplified version of VPACC could be used, implementing the airflow rate error and the temperature error only.

\subsubsection{Parameters}

For each process error to which CUSUM analysis is to be applied, there is a set of parameters that must be known and/or specified. These are the expected value of the process error $(\hat{x})$, the process error standard deviation $(\hat{\sigma})$, the slack parameter $(k)$, and the alarm limits for the $S$ and $T$ CUSUMs $\left(h_{S}\right.$ and $\left.h_{T}\right)$. For the purposes of this study, the expected value and standard deviation of the process error were determined by analysis of a short period of fault-free operation from a particular data source. CUSUM analysis was performed for each error using an expected value and standard deviation representative of the VAV boxes from each site. These parameters will be referred to as the VPACC statistical parameters throughout the remainder of this paper. The slack parameter $k=3$ and alarm limits $h_{S}=h_{T}=900$ are the same for all data sources. To exceed the alarm limit value using one min data, an error that is five standard deviations from the mean would have to persist for $7.5 \mathrm{~h}$. When a CUSUM does exceed the alarm limit, it is reset to zero and the calculations resume. Each CUSUM is also reset to zero during unoccupied periods (and during the first hour of occupancy, to allow steady state conditions to develop). Thus, the severity of a fault can be established from the number of alarms over a period of time.

\subsubsection{Special Cases}

\subsubsection{No Discharge Air Temperature Sensor}

Many VAV boxes are equipped with a discharge air temperature sensor, which VPACC needs to calculate the reheat coil differential temperature error. If a discharge air temperature sensor is not available, a simplified version of VPACC could be used, implementing the airflow rate error, the absolute value of the airflow rate error, and the temperature error only. In this case, a leaking reheat coil valve (or, in the case of electric reheat, staged reheat enabled "on" in the cooling mode) would not be detected unless it was so extreme that the VAV box was unable to maintain the zone temperature at the set point, thereby causing alarms due to excessive values of $S_{T}$. 


\subsubsection{Pressure Dependent}

In some VAV boxes, the damper is controlled directly in response to zone temperature without an intermediate determination of an airflow setpoint. Qerror and $\left|Q_{\text {error }}\right|$ do not exist for a pressure dependent VAV box. In this case, a stuck damper may go undetected. In the case where the zone is overcooled, the reheat coil valve will open (or staged reheat will be enabled "on" if electric reheat is employed) and compensate for the fault, masking its existence. In the case where the zone is undercooled, the rising zone temperature may create alarms due to excessive values of $S_{T}$.

\subsubsection{No Reheat}

Some VAV boxes do not have reheat capabilities. Others do not have reheat available part of the year because a two pipe hydronic system is being used for chilled water at that time. Since the VAV box cannot take any control action to increase zone temperature, a negative temperature error does not necessarily indicate a fault. In this situation, only the $S_{T}$ CUSUM will be calculated for $T_{\text {error }}$.

\subsubsection{Dual Duct}

In a dual duct VAV box, there is no reheat coil (and no electric reheat). Instead there are two air inlets, namely, a cold deck and a hot deck. Each air inlet has a damper and differential pressure sensor. For this arrangement, two airflow errors $\left(Q_{\text {error,hot }}\right.$ and $\left.Q_{\text {error,cold }}\right)$ and two absolute value airflow errors $\left(\left|Q_{\text {error, hot }}\right|\right.$ and $\left.\left|Q_{\text {error, cold }}\right|\right)$ will be calculated. No $\Delta T_{\text {error }}$ will be calculated as there is no reheat capability. 


\section{Data Sources}

\subsection{SITE-1}

SITE-1 is a large federal office building in California. Air handling unit data were collected from three constant-volume AHUs with enthalpy-based economizers. VAV box data were collected from eight single-duct, pressure independent, cooling-only VAV boxes. Stand-alone software was configured by facility personnel to automatically collect data from the appropriate equipment controllers at $5 \mathrm{~min}$ intervals, generate trend data files, and e-mail those files to the researchers.

\subsection{SITE-2}

SITE-2 is a restaurant with a pre-existing arrangement for remote monitoring. The monitoring firm agreed to provide the researchers with $1 \mathrm{~min}$ data collected from one constant-volume AHU with a temperature-based economizer. Only those points already being trended were available. Mixed air temperature was not one of those points. Although the economizer is controlled to maintain the supply air temperature at a setpoint, the heating and cooling coil valves are controlled to maintain zone temperature, not supply air temperature, at a setpoint. Therefore, the supply air temperature setpoint is not a meaningful quantity in all modes of operation. In addition, the zone temperature setpoint, another point not being trended, is varied based on a fixed schedule. The zone temperature setpoint is also occupant adjustable. A modified version of APAR was developed in which the modes are determined as described earlier, but only a subset of the rules, those not involving mixed air temperature or supply air temperature setpoint, were evaluated.

\subsection{SITE-3}

SITE-3 is a community college campus. Data were collected from nine single-duct, pressure independent VAV boxes with hydronic reheat. The reheat coils are supplied with hot water by a two-pipe system (a single piping system is used for chilled water during cooling season and hot water during heating season). During the cooling season (the time period during which the data was collected) hot water for reheat is not available, so the VAV boxes were treated as if they were cooling-only. The building control system was configured by facility personnel to trend data from the appropriate equipment controllers at one min intervals.

\subsection{SITE-4}

SITE-4 is a university campus. It was originally intended that the appropriate data would be trended using the university's advanced control system, which would allow the researchers to access the equipment controllers via the Internet. Due to time and personnel constraints, it was not possible to establish this mode of data collection. However, three weeks of preliminary 1 min data were trended by facility personnel and made available to the researchers. Data were collected from two variable-air-volume AHUs with enthalpy-based economizers, as well as from eight pressure independent VAV boxes with hydronic reheat. These systems operate 24 hours per day, 7 days per week. There is no occupied/unoccupied scheduling. 


\section{Results}

Examples of faulty operation are presented from each of the sites.

\subsection{SITE-1}

\subsubsection{AHU Supply Air Temperature Fault}

Figure 4.1 shows a plot of temperature and control signal data from one of the AHUs at SITE-1, labeled AHU-A. Based on the control signals (cooling coil valve is black, heating coil valve is not shown, but remains fully closed, mixing box damper is not shown, but remains aligned for minimum ventilation) APAR determines that AHU-A is operating in Mode 4 (mechanical cooling with minimum outdoor air), then applies the rules for this mode. One of the rules for Mode 4 is Rule 19, which states that if the average cooling coil valve control signal is fully open (within $1 \%$ ) and the difference between supply air temperature and supply air temperature setpoint is greater than $1.7^{\circ} \mathrm{C}\left(3.0^{\circ} \mathrm{F}\right)$, the cooling coil valve is saturated and a persistent supply air temperature error exists. Figure 4.1 shows the supply air temperature (blue), varies from $9^{\circ} \mathrm{C}$ to $13{ }^{\circ} \mathrm{C}\left(50{ }^{\circ} \mathrm{F}\right.$ to $\left.55^{\circ} \mathrm{F}\right)$ and the supply air temperature setpoint (red) is fixed at $7{ }^{\circ} \mathrm{C}\left(45^{\circ} \mathrm{F}\right)$ an unreasonably low value for this application. Clearly, the supply air temperature error is greater than $1.7^{\circ} \mathrm{C}\left(3.0^{\circ} \mathrm{F}\right)$, therefore APAR has detected a fault. Facility personnel confirmed that the fault was the result of inappropriate operator intervention.

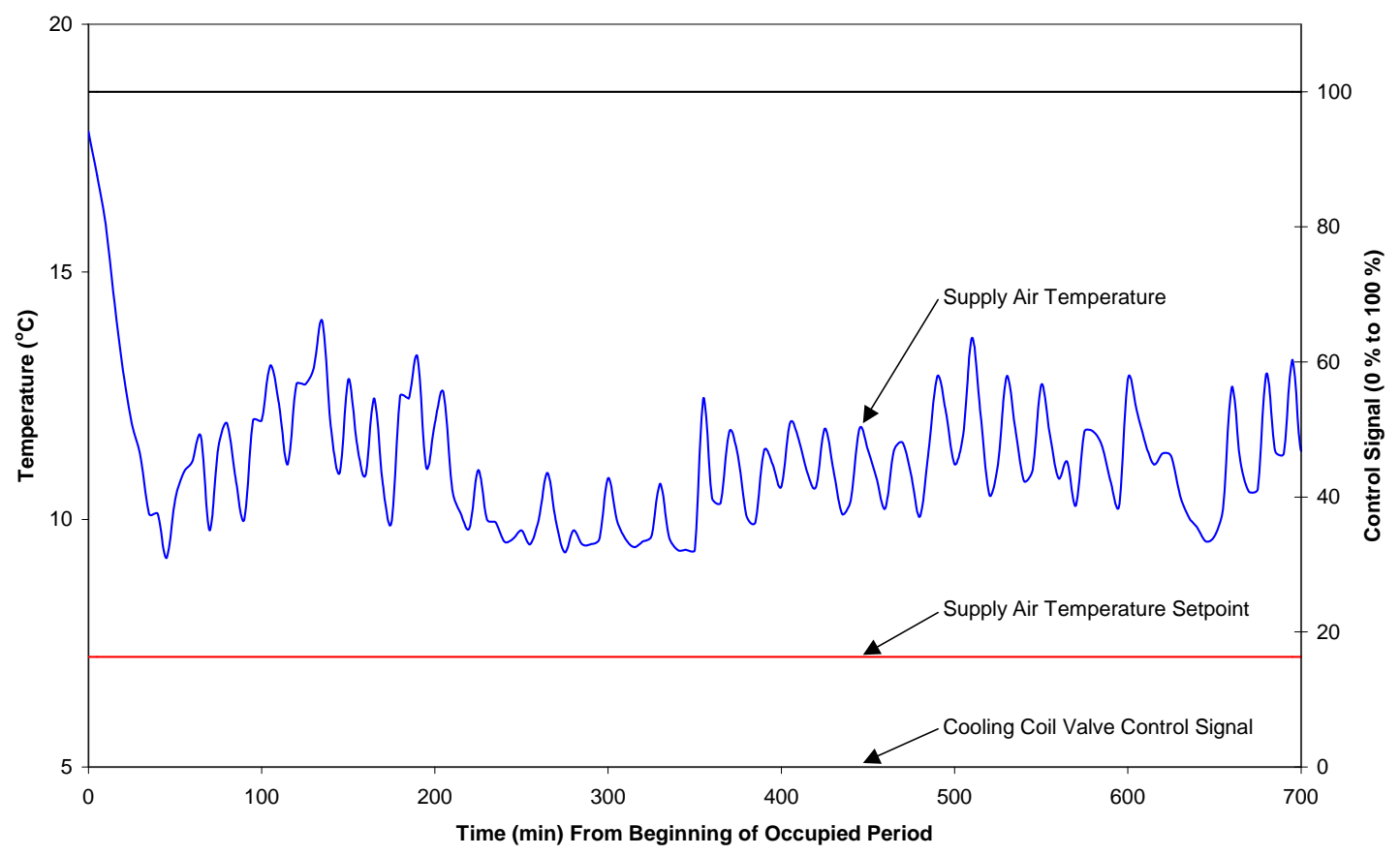

Figure 4.1 SITE-1 AHU-A Supply Air Temperature Fault 


\subsubsection{AHU Mode Switch Fault}

Figure 4.2 shows a plot of the control signals, including the cooling coil valve (blue), heating coil valve (red), and mixed air damper (green), from another of the AHUs at SITE-1, labeled AHU-B. Of interest is the $3 \mathrm{~h}$ period from $420 \mathrm{~min}$ until $600 \mathrm{~min}$ after the beginning of the occupied period. During this $3 \mathrm{~h}$ time span, APAR observes AHU operation in three different modes: Mode 2 (cooling with outdoor air - heating coil valve less than $1 \%$ open, cooling coil valve less than $1 \%$ open, mixed air damper greater than $26 \%$ open [25\% is the position for minimum outdoor air fraction to meet ventilation requirements plus a $1 \%$ threshold]), Mode 3 (mechanical cooling with $100 \%$ outdoor air - heating coil valve less than $1 \%$ open, cooling coil valve greater than $1 \%$ open, mixed air damper greater than $99 \%$ open), and Mode 4 (mechanical cooling with minimum outdoor air - heating coil valve less than $1 \%$ open, cooling coil valve greater than $1 \%$ open, mixed air damper less than $26 \%$ open). Rule 28 is evaluated regardless of mode, stating that if more than seven mode switches are recorded in $1 \mathrm{~h}$, a fault has been detected. In this case, the AHU switches between modes 26 times over the $3 \mathrm{~h}$ period, satisfying Rule 28 for each of the $3 \mathrm{~h}$. The most probable cause of this fault is incorrect tuning of the temperature control PID loop in the AHU controller. A follow up with facility personnel confirmed the existence of the fault as well as the diagnosis.

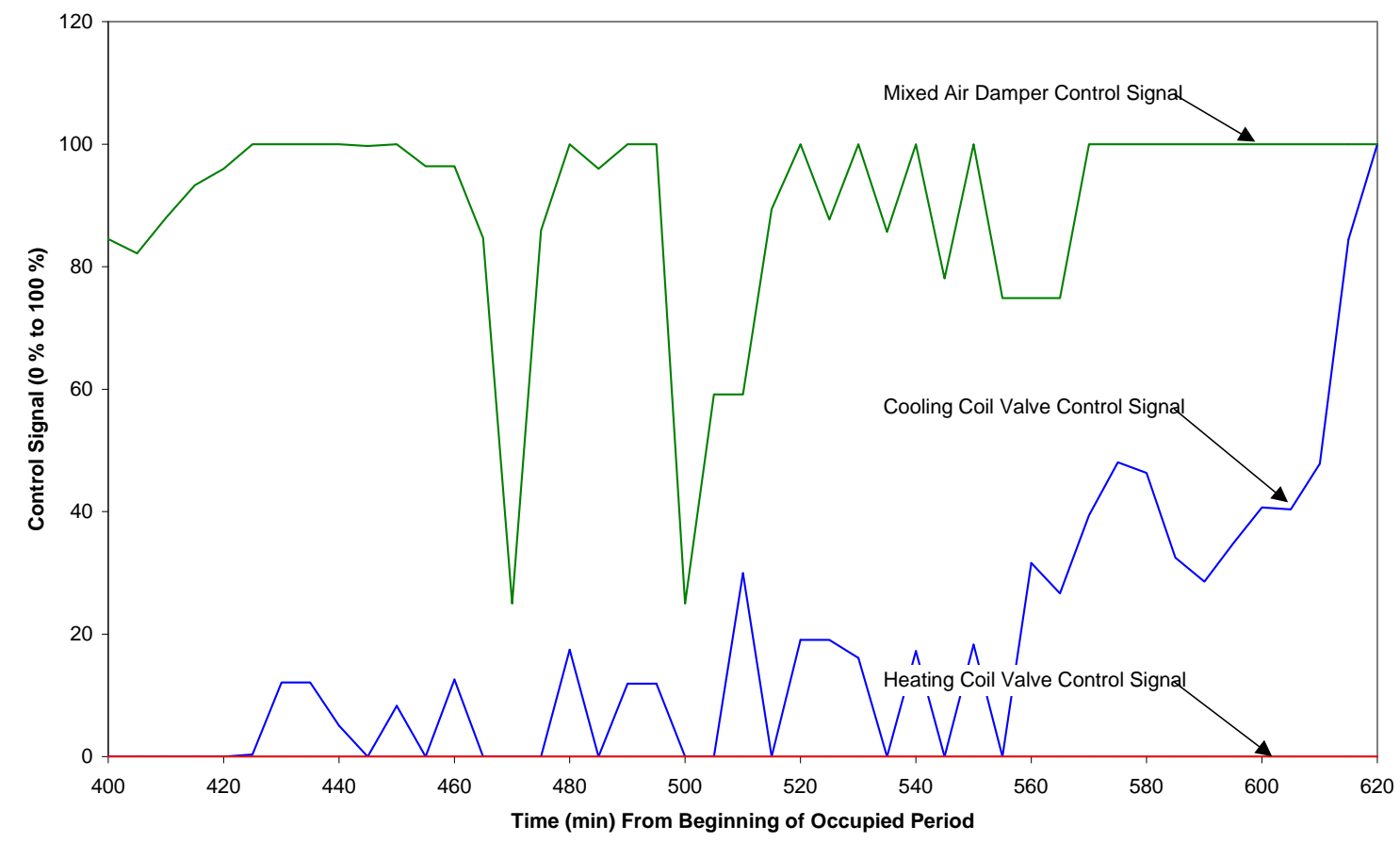

Figure 4.2 SITE-1 AHU-B Mode Switch Fault

\subsubsection{AHU Simultaneous Heating and Cooling Fault}

Figure 4.3 shows a plot of the control signals from another of the AHUs at SITE-1, labeled AHU-C. During a 25 min time span starting 230 min after the beginning of the occupied period, 
the heating coil valve (red) is open while the mixing box damper (green) is $100 \%$ open. For a 10 min period during this time span (from $235 \mathrm{~min}$ until $245 \mathrm{~min}$ ) both the heating coil valve and the mixing box damper are $100 \%$ open. This combination of control signals is inconsistent with any known mode, so APAR classifies this period of operation as Mode 5 (unknown mode) and evaluates the rules associated with this mode. Rule 23, one of the rules associated with Mode 5 , states that if the average position of the heating coil valve is greater than $1 \%$ and the average position of the mixing box damper is more than $26 \%(1 \%$ more than the minimum for ventilation), then a fault has been detected, since the AHU is simultaneously heating and cooling/economizing. The most probable cause of this fault is an AHU controller sequencing error. A follow up with facility personnel confirmed this diagnosis. The facility personnel then modified the controller sequencing logic. After the modification, the fault was not detected again.

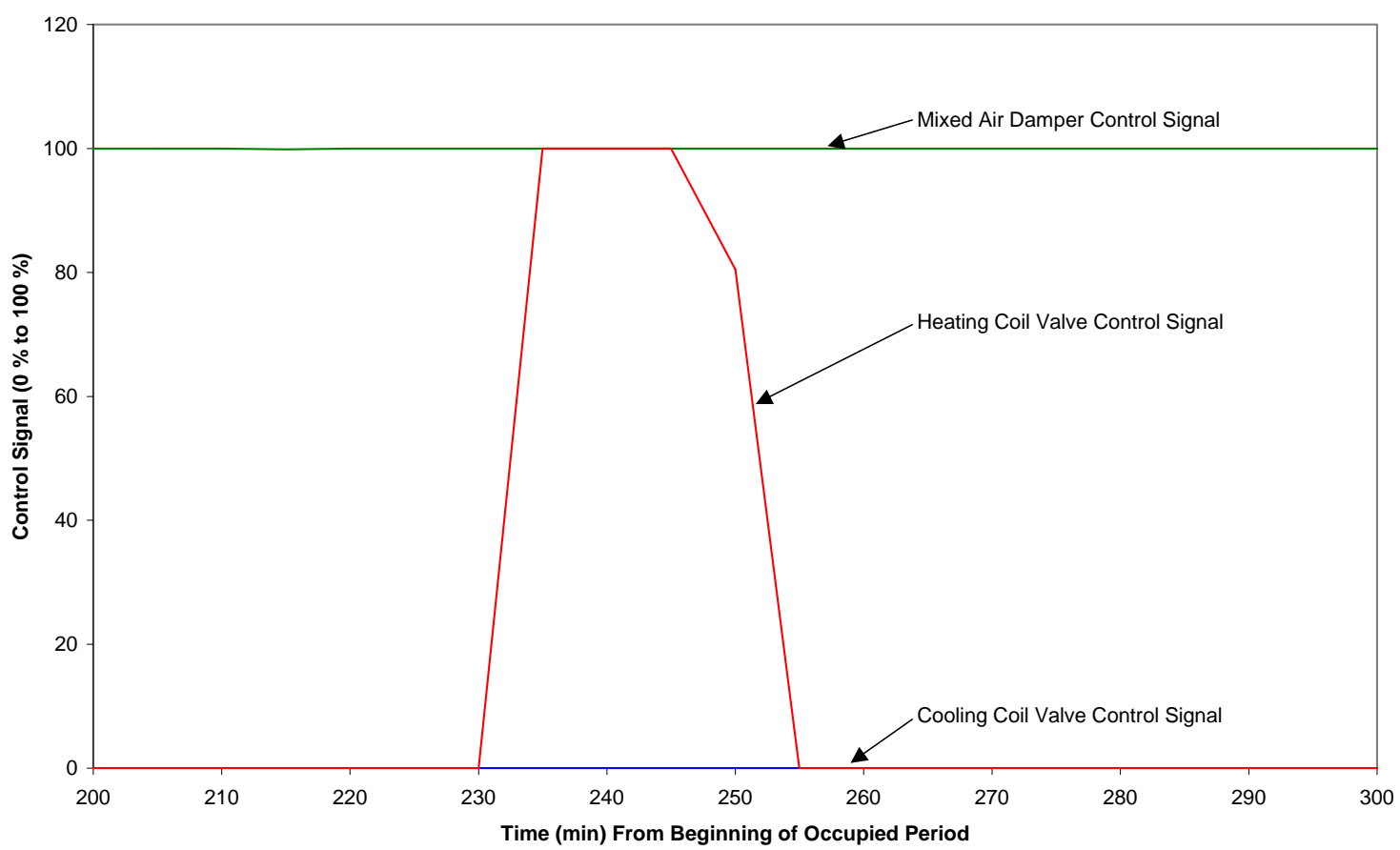

Figure 4.3 SITE-1 AHU-C Simultaneous Heating and Cooling Fault

\subsubsection{AHU Temperature Sensor / Damper Fault}

Figure 4.4 shows another plot of temperatures and control signals from AHU-C. From $220 \mathrm{~min}$ until $700 \mathrm{~min}$ after the beginning of the occupied period (approximately an eight hour time span), the mixed air damper (green) is positioned for $100 \%$ outdoor air. The cooling coil valve (not shown) ranges from fully closed to fully open and the heating coil valve (not shown) remains fully closed. Based on this combination of control signals, APAR places AHU-C in Mode 3 (mechanical cooling with $100 \%$ outdoor air) and evaluates the rules for Mode 3 . One of these is Rule 10, which states that if the outdoor air and mixed air temperature differ by more than $1.7^{\circ} \mathrm{C}$ $\left(3.0^{\circ} \mathrm{F}\right)$, a fault has been detected since the outdoor air and mixed air temperature should be the same when the mixed air damper is positioned for $100 \%$ outdoor air. During this time, the 
mixed air temperature (brown) remains approximately $3{ }^{\circ} \mathrm{C}\left(5^{\circ} \mathrm{F}\right)$ greater than the outdoor air temperature (blue), satisfying Rule 10. The most probable causes of this fault include a mixed air or outside air temperature sensor error or a mixed damper leakage or actuator failure. A follow up with facility personnel revealed that the fault was caused by the location of the outdoor air temperature sensor on the roof of the building, remote from the AHU outside air intake. Although the location of the sensor is less than ideal, it was not possible for the building staff to relocate it.

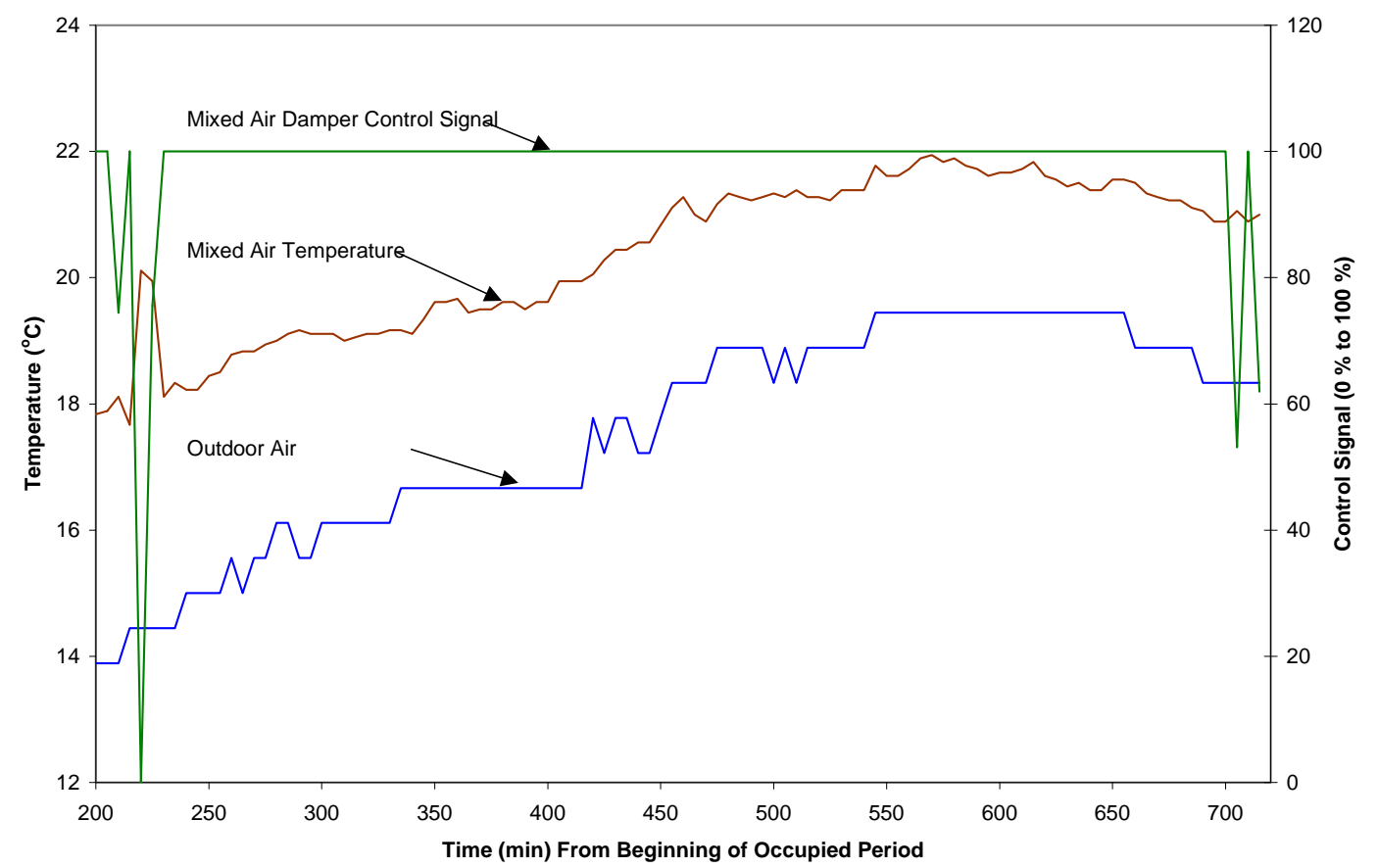

Figure 4.4 SITE-1 AHU-C Temperature Sensor / Damper Fault

\subsubsection{VAV Box Zone Temperature Fault}

Figure 4.5 shows a plot of the zone temperature and the related CUSUM from one of the VAV boxes at SITE-1, labeled VAV Box - A. Approximately 500 min after the beginning of the occupied period the supply air temperature from the air handling unit (brown) begins to rise, reaching a peak of $32{ }^{\circ} \mathrm{C}\left(90^{\circ} \mathrm{F}\right)$ at $880 \mathrm{~min}$. The zone temperature (green) closely tracks the supply air temperature from the AHU, peaking at approximately the same temperature and at approximately the same time. In this operating region the zone temperature error is defined as the difference between the zone temperature and the cooling setpoint. This zone temperature error is normalized, using sitewide statistical parameters determined from one month of training data from SITE-1, by subtracting the average zone temperature error $\left(0.34{ }^{\circ} \mathrm{C}\left[0.61{ }^{\circ} \mathrm{F}\right]\right)$, then dividing by the standard deviation $\left(1.0^{\circ} \mathrm{C}\left[1.8^{\circ} \mathrm{F}\right]\right)$. The slack parameter $\mathrm{k}$ is set at three, so at $630 \mathrm{~min}$, when the normalized zone temperature error increases to more than three, the positive temperature CUSUM (S_Temp, purple) begins to increase. S_Temp exceeds the alarm limit $\mathrm{h}$ (set at 180, which, with data at 5 min intervals, corresponds to an error five standard deviations greater than average for $7.5 \mathrm{~h}$ ) at $1000 \mathrm{~min}$ after the beginning of the occupied period. Although 
building staff were notified of the detection of this fault, they were unable to investigate further. Clearly the cause of the problem is the high AHU supply air temperature, however it is unknown if there was an AHU fault. It is possible that the AHU supply air temperature setpoint was high due to heating demand from other VAV boxes served by the AHU. This may be a system level fault, resulting from the hierarchical relationship between different pieces of equipment in the HVAC system.

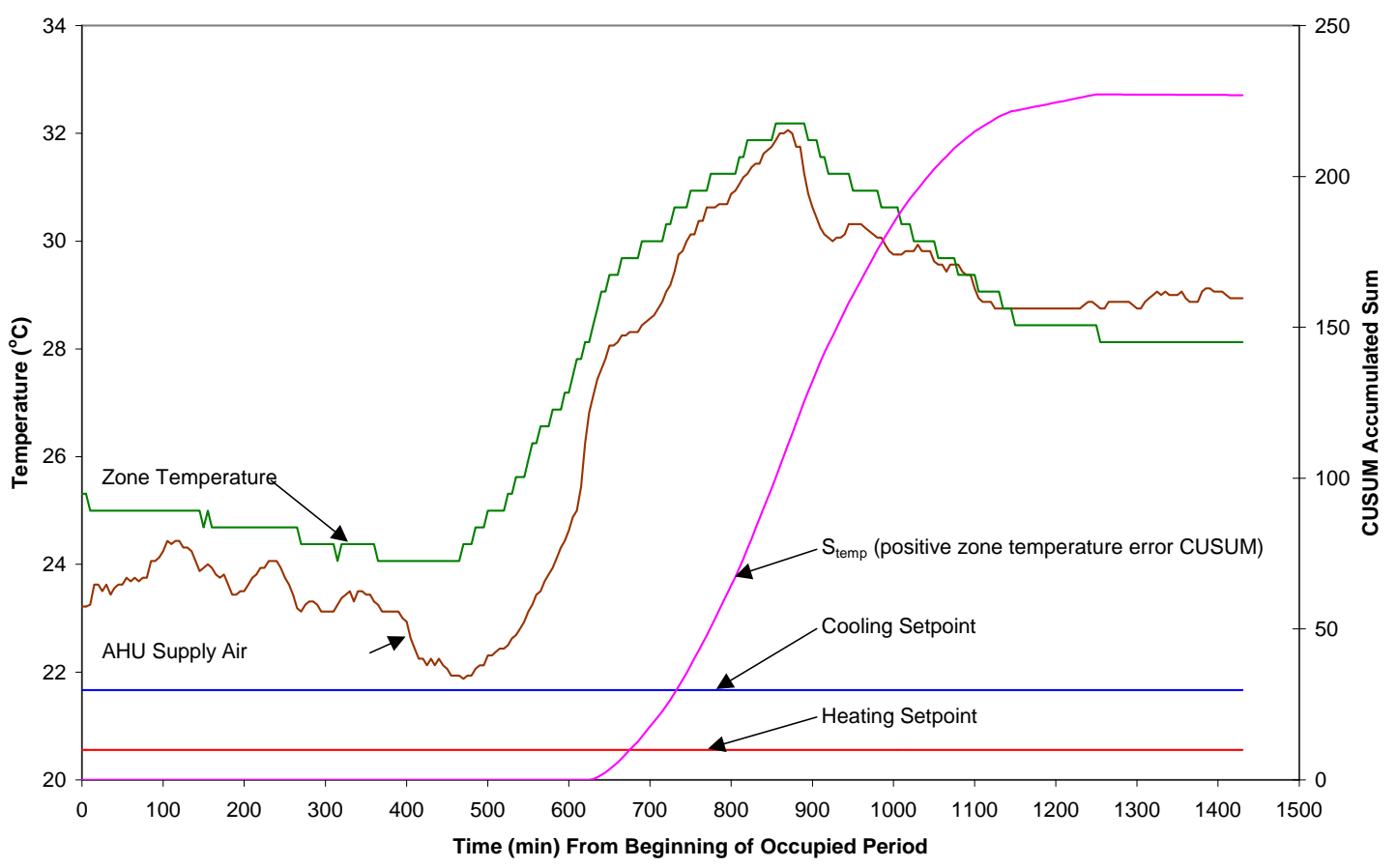

Figure 4.5 SITE-1 VAV Box-A Zone Temperature Fault

\subsection{SITE-2}

\subsubsection{AHU Saturated Cooling Coil}

Figure 4.6 shows a plot from an AHU at SITE-2, labeled AHU-A. For the first $450 \mathrm{~min}$ of occupancy, the heating coil (red) remains closed, the mixed air damper (green) is aligned for the minimum outside air fraction, and the cooling coil valve (blue) is saturated at $100 \%$. Based on these control signals, APAR determines that AHU-A is operating in Mode 4 (mechanical cooling with minimum outdoor air). This AHU is a single zone unit in which the cooling coil valve is controlled to maintain zone temperature at the zone temperature setpoint rather than supply air temperature at the supply air temperature setpoint. One of the rules associated with Mode 4 is Rule 20, which, as modified for SITE-2, states that if the average cooling coil valve position is greater than $99 \%$ open, the valve is saturated and any additional cooling load will cause the zone temperature to drift. When this rule is satisfied, APAR declares a warning rather than a fault, since the supply air temperature error cannot be evaluated (see the description of SITE-2 in 3.2, 
for further explanation). The zone temperature (brown) is maintained between $20^{\circ} \mathrm{C}\left(68^{\circ} \mathrm{F}\right)$ and $22{ }^{\circ} \mathrm{C}\left(72{ }^{\circ} \mathrm{F}\right)$, a reasonable range for the application. There are many possible diagnoses including: temperature sensor error, cooling coil valve actuator failure, inappropriate operator/occupant intervention, temperature control PID loop tuning error, or sequencing logic error. On the other hand, it is entirely possible that this warning was caused by some unusual activity in the zone which generated a large cooling load. A follow up with facility personnel was not possible.

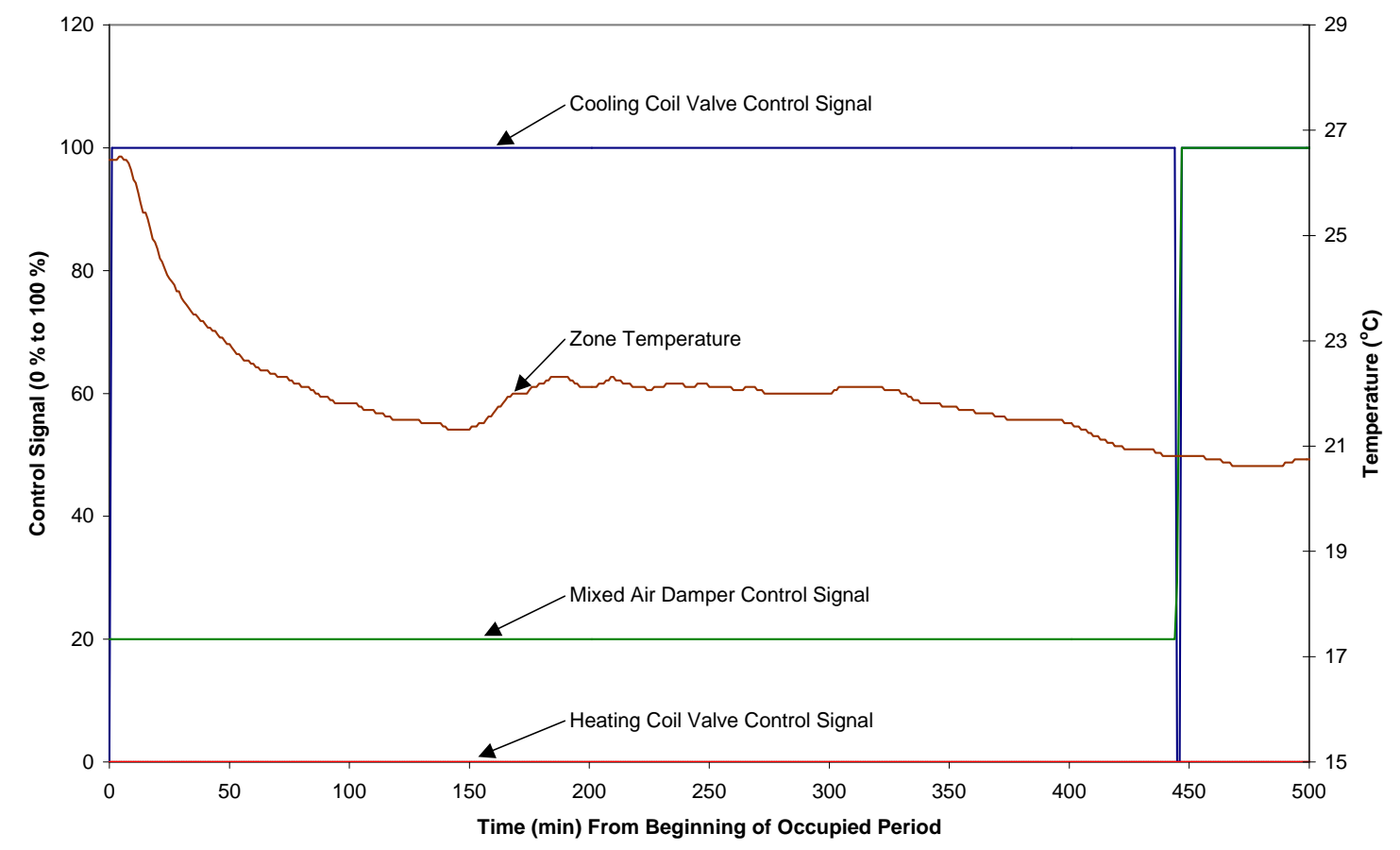

Figure 4.6 Site-2 AHU-A Saturated Cooling Coil Fault

\subsubsection{AHU Mode Switch Fault}

Figure 4.7 shows a plot of the control signals from AHU-A, including the cooling coil valve (blue), heating coil valve (red), and mixed air damper (green). During the first three hours of the occupied period APAR observes AHU-A cycle between two different modes: Mode 2 (cooling with outdoor air - heating coil valve less than $1 \%$ open, cooling coil valve less than $1 \%$ open, mixed air damper open more than $21 \%$ [20\% is the minimum for ventilation]) and Mode 3 (mechanical cooling with $100 \%$ outdoor air - heating coil valve less than $1 \%$ open). Rule 28 is evaluated regardless of mode, stating that if more than seven mode switches are recorded in an hour, a fault has been detected. In this case, the AHU switches between the two modes 72 times during the three hour period, satisfying Rule 28 for each of the three hours. The most probable cause of this fault is either a sequencing error or incorrect tuning of the temperature control PID loop in the AHU controller. The existence of the fault was confirmed by the monitoring firm and reported to the facility personnel, who were unable to investigate further. 


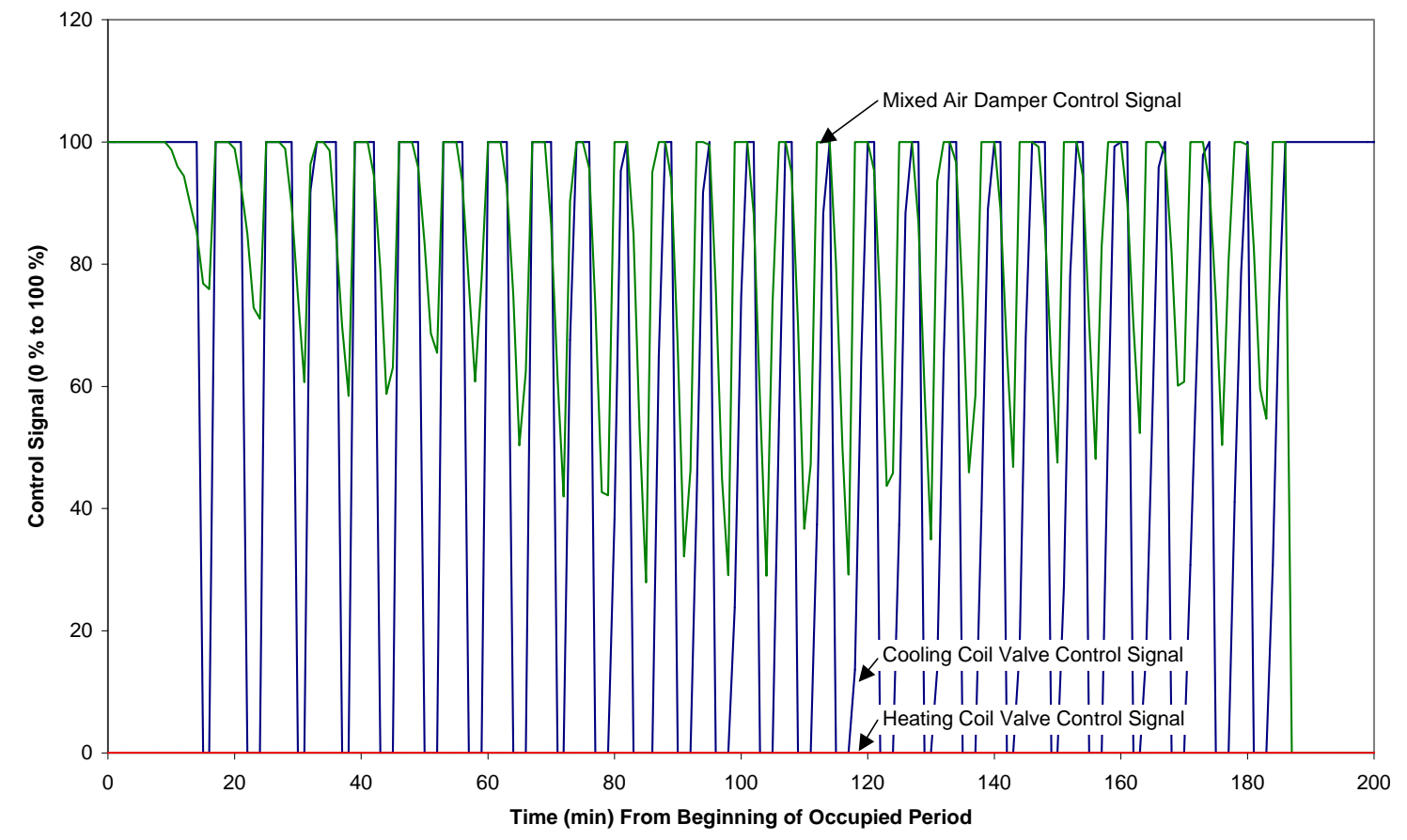

Figure 4.7 Site-2 AHU-A Mode Switch Fault

\subsection{SITE-3}

Results from 20 weeks of field testing for each of the nine VAV boxes are summarized in Table 4.1. The number reported in a cell represents the total number of alarms over the 20 week period of a particular CUSUM and a particular VAV box. The total number of alarms for each box are also reported in the last column of Table 4.1. Note that the total excludes $S_{Q}$ and $T_{Q}$ because they are in essence a subset of $S_{|Q|}$. That is, an alarm of $S_{Q}$ or $T_{Q}$ will always produce an alarm of $S_{|Q|}$, although $S_{|Q|}$ may alarm first if, for instance, the airflow errors are predominantly positive but include some large negative errors as well. Because reheat was not available, VPACC did not monitor the zone temperature error in the heating mode.

The VPACC results in Table 4.1 indicate that VAV boxes E and I are performing poorly and VAV boxes F, G, and $\mathrm{H}$ are performing well. The other VAV boxes are performing somewhere between these two extremes. Closer inspection of the trended data for VAV box E reveals that the zone temperature routinely exceeds the cooling set point of $22.2^{\circ} \mathrm{C}\left(72{ }^{\circ} \mathrm{F}\right)$ by $2.2{ }^{\circ} \mathrm{C}\left(4^{\circ} \mathrm{F}\right)$ to $3.3^{\circ} \mathrm{C}\left(6^{\circ} \mathrm{F}\right)$. This produces 70 alarms of $S_{T}$ per week on average and nine weeks with 100 to 115 alarms of $S_{T}$. It is common for the discharge air temperature to this zone to be $15.6{ }^{\circ} \mathrm{C}\left(60^{\circ} \mathrm{F}\right)$ to $21.1{ }^{\circ} \mathrm{C}\left(70^{\circ} \mathrm{F}\right)$, indicating that the capacity problems are due at least in part to the manner in which the AHU is being controlled and/or to the design of the system. Another VAV box (C) on the same AHU routinely operates in the heating mode $1.1{ }^{\circ} \mathrm{C}\left(2^{\circ} \mathrm{F}\right)$ to $1.7^{\circ} \mathrm{C}\left(3^{\circ} \mathrm{F}\right)$ below the heating set point of $22.2^{\circ} \mathrm{C}\left(72{ }^{\circ} \mathrm{F}\right)$. The lack of reheat makes it impossible for the AHU to satisfy the two zones when one requires cooling and the other heating. Operational changes to 
reduce the minimum airflow rates for the heating mode may help alleviate the problem of overcooling certain zones.

Table 4.1

VPACC results for the field data sets.

\begin{tabular}{|l|r|r|r|r|r|r|}
\hline \multirow{2}{*}{ VAV Box } & \multicolumn{6}{|c|}{ Number of Alarms } \\
\cline { 2 - 7 } & \multicolumn{1}{|c|}{$S_{Q}$} & \multicolumn{1}{|c|}{$T_{Q}$} & \multicolumn{1}{c|}{$S_{T}$} & $T_{T}$ & $S_{|Q|}$ & Total $^{\mathbf{1}}$ \\
\hline $\mathrm{A}$ & 0 & 29 & 36 & 0 & 29 & 65 \\
$\mathrm{~B}$ & 0 & 125 & 62 & 0 & 125 & 187 \\
$\mathrm{C}$ & 0 & 38 & 42 & 0 & 38 & 80 \\
$\mathrm{D}$ & 0 & 104 & 52 & 0 & 105 & 157 \\
$\mathrm{E}$ & 0 & 70 & 1406 & 0 & 72 & 1478 \\
$\mathrm{~F}$ & 0 & 1 & 0 & 0 & 1 & 1 \\
$\mathrm{G}$ & 0 & 0 & 1 & 0 & 0 & 1 \\
$\mathrm{H}$ & 0 & 10 & 3 & 0 & 10 & 13 \\
$\mathrm{I}$ & 0 & 674 & 3 & 0 & 674 & 677 \\
\hline
\end{tabular}

The VPACC results in Table 4.1 indicate that box I has severe airflow control problems. The minimum number of alarms of $T_{Q}$ in a week is seven, while the average is close to 34 . This indicates that the flow rate to the zone is consistently less than the set point airflow rate. This is true whether the VAV box operates in the heating or cooling mode. This seems to indicate that the static pressure is not sufficient to deliver the amount of air needed in the zone. Due to the nature of the flow error, $\mathrm{S}_{|Q|}$ alarms at the same times as $T_{Q}$.

VAV boxes $F$ and $G$ alarm only one time each over the twenty weeks of testing. Inspection of the process data supported the findings of VPACC, namely, that the control was quite good. VAV box $\mathrm{H}$ also performed well, with 11 of the 13 alarms occurring during the week of June 1016, 2002. For much of the first part of that week, the AHU supply air temperature ranged from $18.3^{\circ} \mathrm{C}\left(65^{\circ} \mathrm{F}\right)$ to $21.1^{\circ} \mathrm{C}\left(70^{\circ} \mathrm{F}\right)$, causing the zone temperature to exceed its cooling set point of $22.2^{\circ} \mathrm{C}\left(72^{\circ} \mathrm{F}\right)$ by nearly $1.1^{\circ} \mathrm{C}\left(2^{\circ} \mathrm{F}\right)$. Hence the problem does not appear to be with the control of the VAV box. The controller operated in the heating mode during most of the testing and this contributed to the low number of alarms because only flow control was monitored in the heating mode.

The performance of the remaining four VAV boxes (A,B,C, and D) is a little more difficult to assess. A significant number of the alarms for each occur during five weeks of the testing, namely, May 20-26, 2002, May 27 to June 2, 2002, June 10-16, 2002, July 8-14, 2002, and July 22-28, 2002. Specifically, 55 of 65 alarms for A, 111 of 187 alarms for B, 75 of 80 alarms for C, and 101 of 156 alarms for $\mathrm{D}$ occur during those five weeks.

The problem in the weeks of May 20-26, 2002 and May 27 to June 2, 2002 is associated with the AHU temperature control. All four boxes (as well as E, which is served by the same AHU) have a significant number of $S_{T}$ alarms during these two weeks. Closer inspection of the trended data indicates the discharge air temperatures to the zones exceeded $23.9^{\circ} \mathrm{C}\left(75^{\circ} \mathrm{F}\right)$ for nearly $20 \mathrm{~h}$ 
over the latter part of the first week and the beginning of the second week. Since this time period encompasses the Memorial Day holiday, it is likely that there was a scheduling inconsistency that had the AHU and VAV boxes operating in an occupied mode while the chiller was not running.

The problem in the other three weeks is a sudden drop in the airflow through the four boxes. Figure 4.8 shows the temperature error $\left(T_{\text {error }}\right)$ and airflow error $\left(Q_{\text {error }}\right)$ for box $\mathrm{D}$ during a portion of the week of July 8-14, 2002. The sudden drop in the airflow rate produces large negative airflow errors and positive temperature errors. As shown in Figure 4.9, this results in numerous airflow alarms $\left(T_{Q}\right)$ and one temperature alarm $\left(S_{T}\right)$. This particular problem occurs at six distinct times in the three weeks. The problem occurs at the same time in each of the boxes and also occurs in box E. The fact that the alarms occur at the same time in each of the boxes points to the AHU as the likely source of the problem.

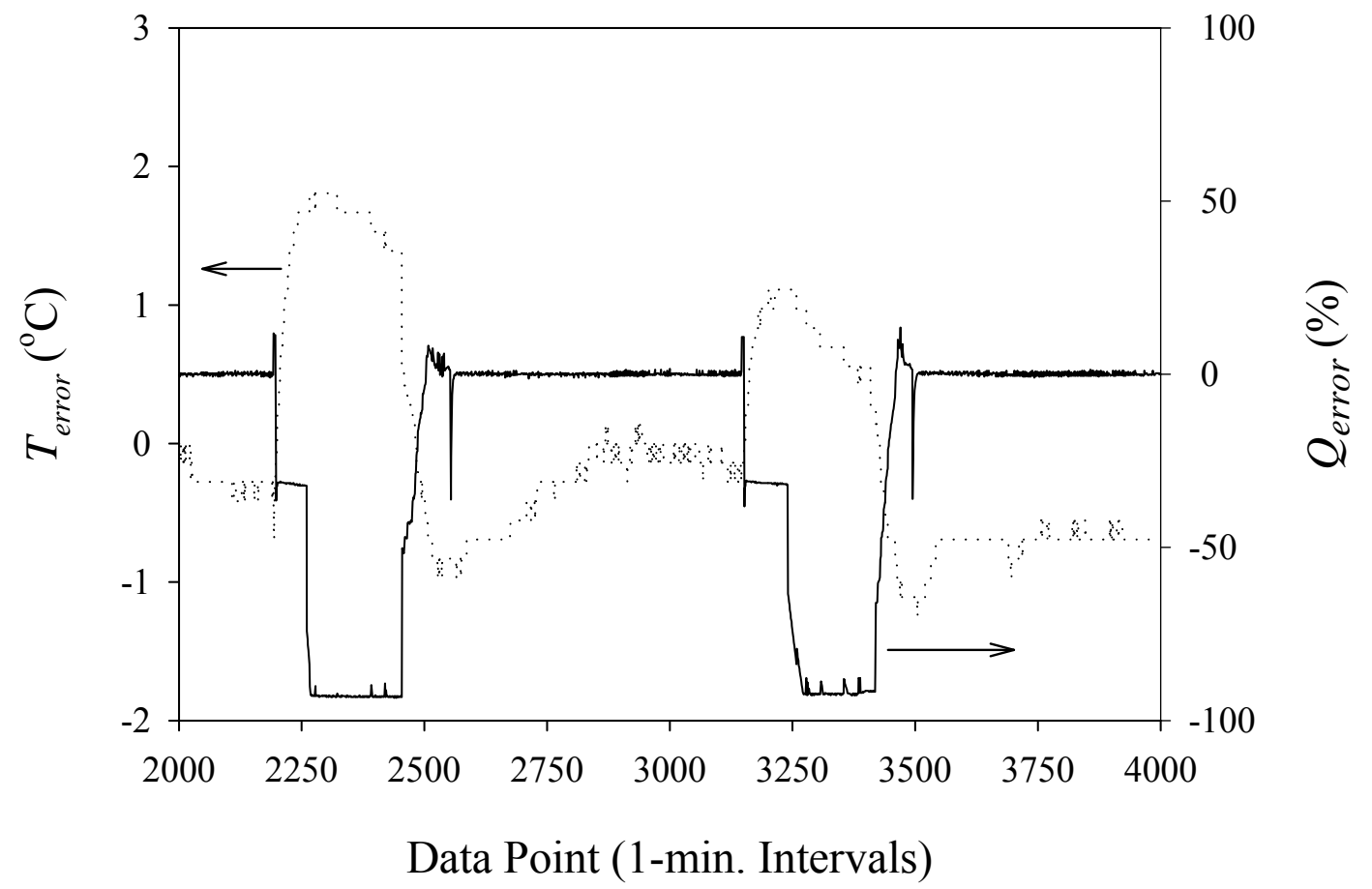

Figure 4.8 Field data for VAV box 101W during the week of July 8, 2002

Considering the remaining 16 weeks of data, the results from VPACC indicate that boxes A and $\mathrm{C}$ are performing fairly well (averaging about 1 alarm per week), while boxes B and D are not doing as well. In general boxes B and D lack capacity in the cooling mode, as indicated by actual airflow rates that are considerably less than the set point values. In the case of box $\mathrm{B}$, the resultant temperature errors can be significant, sometimes exceeding $1.1^{\circ} \mathrm{C}\left(2^{\circ} \mathrm{F}\right)$. Despite the capacity problems, temperature control in zone $\mathrm{D}$ is not a significant problem. 


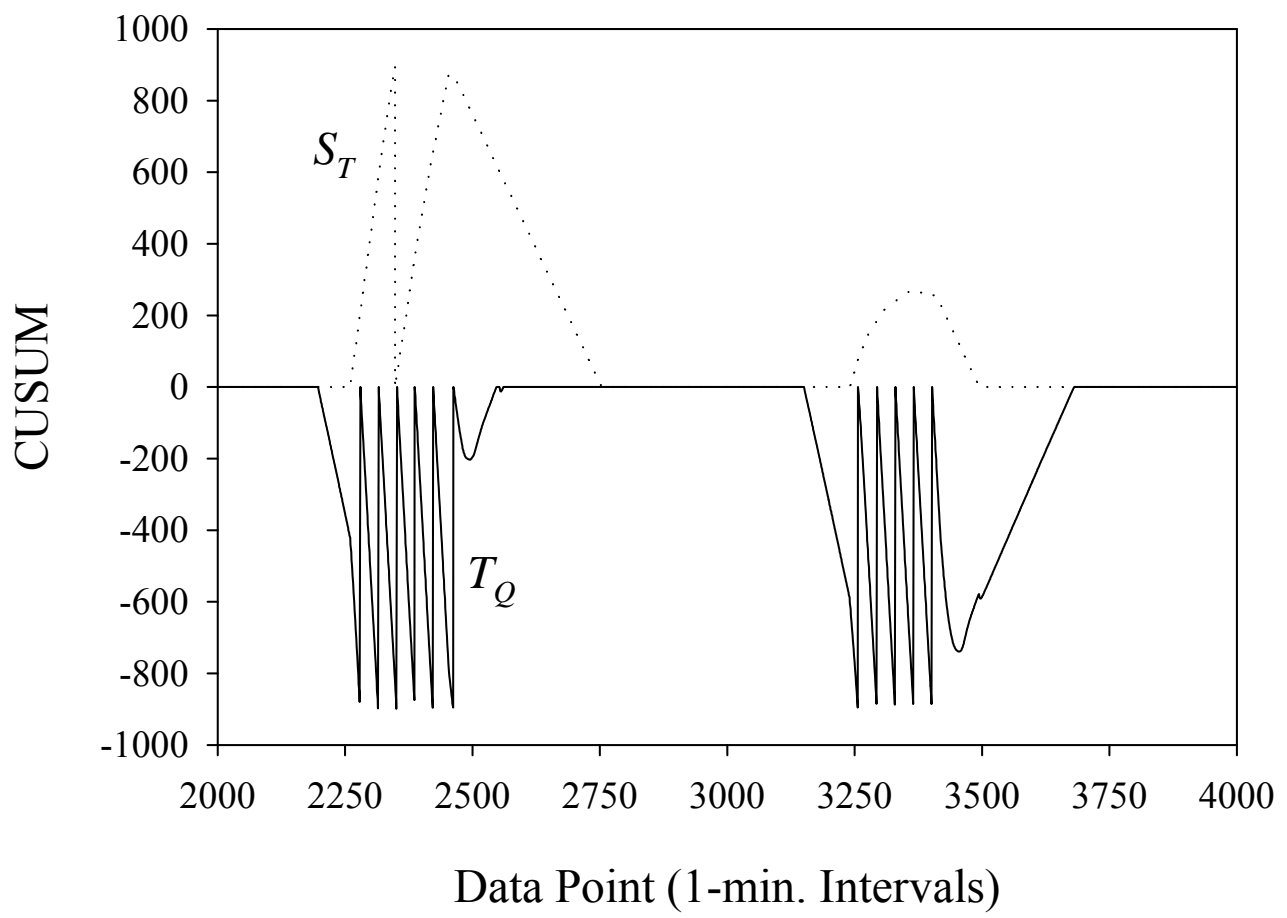

Figure 4.9 VPACC output corresponding to the conditions in Figure 7a

\subsection{SITE-4}

\subsubsection{AHU Simultaneous Heating and Cooling Fault}

Figure 4.10 shows a plot of the control signals from one of the AHUs at SITE-4, labeled AHUA. During the first $1140 \mathrm{~min}(19 \mathrm{~h})$ of the day, the heating coil valve (red) varies between $5 \%$ and $35 \%$ open. Over the same time period, the mixing box damper (green) varies between $25 \%$ and $35 \%$ open. This AHU has two separate mixing box dampers: one allows the minimum amount of outdoor air for ventilation, while the other is for cooling with outside air. The mixing box damper position shown in Figure 4.10 refers to the arrangement for cooling with outside air. The cooling coil is closed throughout the $19 \mathrm{~h}$ time period. This combination of control signals is inconsistent with any known mode of operation, so this period of operation is classified as Mode 5 (unknown mode) and evaluates the rules associated with Mode 5. Rule 23, one of the rules associated with Mode 5 and modified to reflect the mixing box damper arrangement of AHU-A, states that if the average position of the heating coil valve is greater than $1 \%$ and the average position of the mixing box damper is greater than $1 \%$, then a fault has been detected, since the AHU is simultaneously heating and cooling/economizing. The most probable cause of this fault is either a sequencing error or a temperature sensor error related to the specific control strategy implemented in this AHU, in which the cooling coil valve, heating coil valve, and mixing box damper are each controlled by independent PID loops, along with independent temperature sensors and setpoints. Facility personnel were not able to investigate further. 


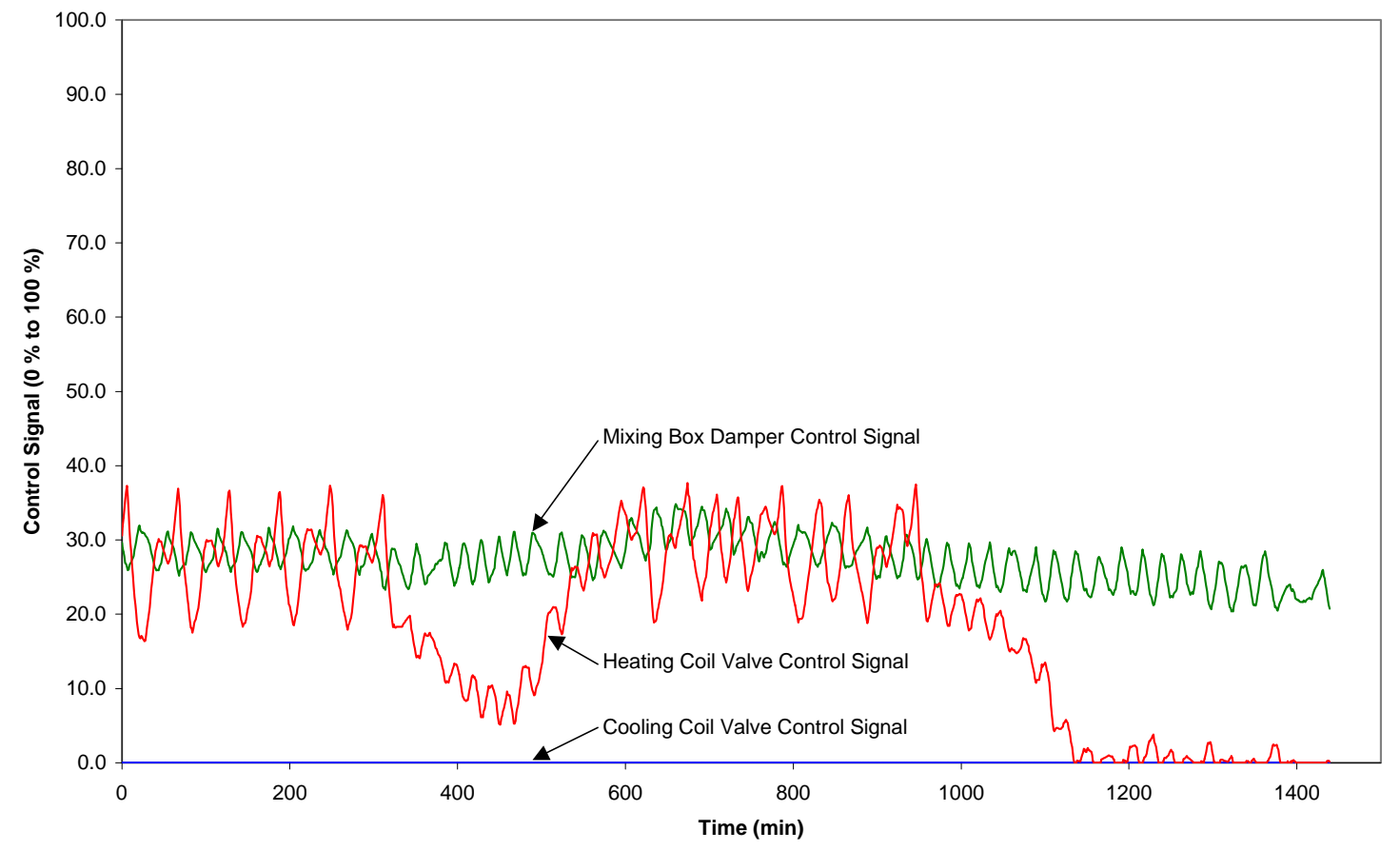

Figure 4.10 SITE-4 AHU Simultaneous Heating and Cooling Fault

\subsubsection{VAV Box Airflow Fault}

A sufficient quantity of data to generate statistical parameters for the SITE-4 VAV boxes was not available, so parameters from SITE-1 were used instead. SITE-1 parameters were chosen because SITE-1 and SITE-4 both have single-duct, pressure-independent VAV boxes. Figure 4.11 shows a plot of zone airflow data and the damper control signal from a VAV box at SITE-4, labeled VAV Box - A. For this entire day, the airflow setpoint (blue) is $0.27 \mathrm{~m}^{3} / \mathrm{s}(580 \mathrm{cfm}$ ). The actual measured airflow rate (red) is in the region of $(0.46 \pm 0.02) \mathrm{m}^{3} / \mathrm{s}[(965 \pm 50) \mathrm{cfm}]$. The damper control signal (not shown) is $0 \%$. The positive airflow CUSUM (purple) steadily increases, exceeding the alarm limit (set at 900, which, with data at 1 min intervals, corresponds to an error five standard deviations greater than average for $7.5 \mathrm{~h}$ ) at $1415 \mathrm{~min}$. A follow up with facility personnel confirmed the existence of the fault. Possible diagnoses include: airflow sensor failure, damper/actuator failure, improper airflow control PID loop tuning, control logic sequencing error, or inappropriate operator intervention. A study to determine robust sets of statistical parameters for a variety of systems is needed; however, this example illustrates the possiblity of using the CUSUM approach without collecting training data from each potential site. 


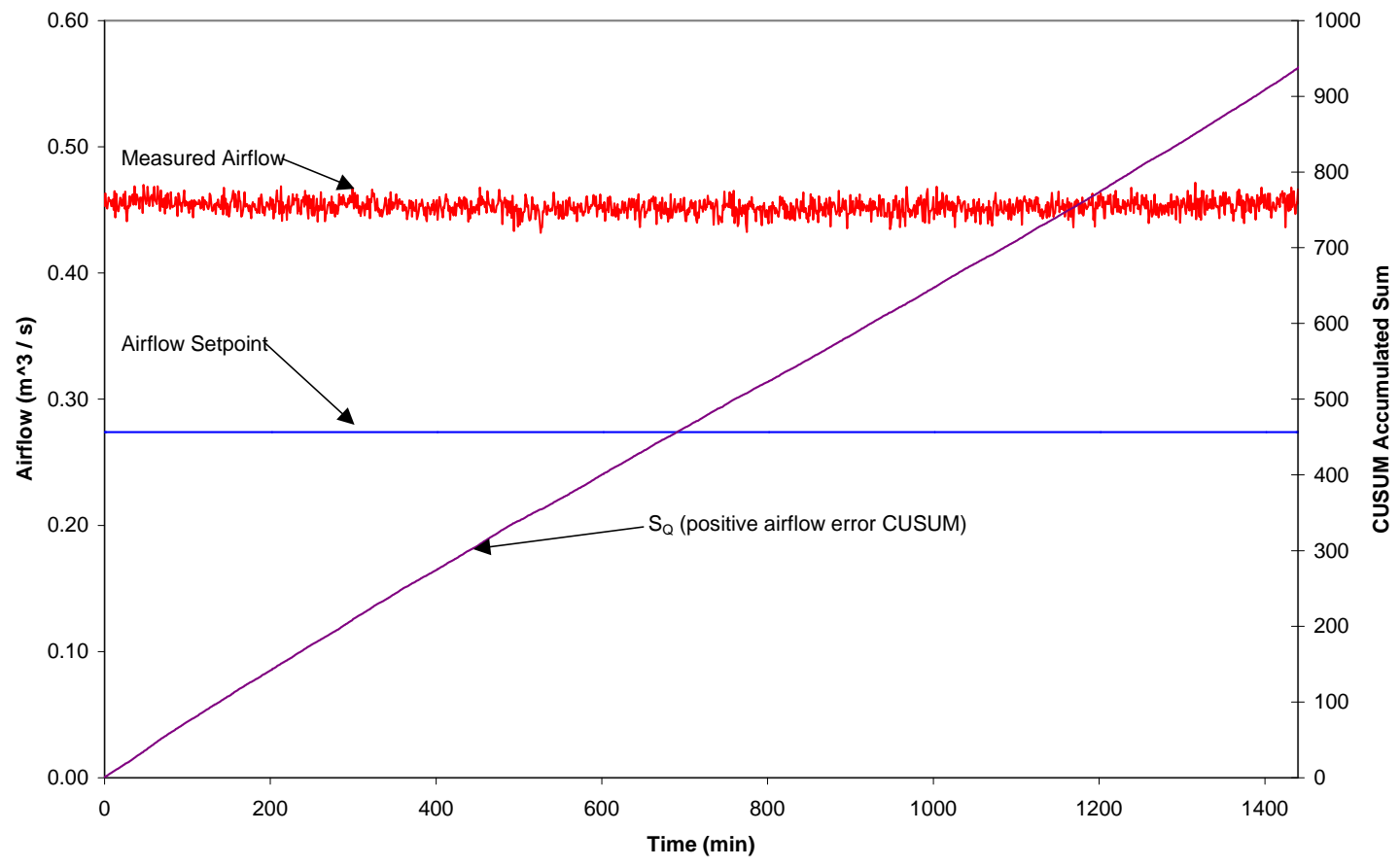

Figure 4.11 SITE-4 VAV Box Airflow Fault

\section{$5 \quad$ Summary and Future Work}

This report presents the results of a field study to evaluate APAR, a rule based FDD tool for AHUs, and VPACC, a statistical quality control based FDD tool for VAV boxes. APAR consists of a set of expert rules, derived from mass and energy balances. Control signals are used to determine the AHU's mode of operation, which identifies the subset of the rules to be evaluated. VPACC uses a small set of process errors, valid for most VAV box control strategies, to measure VAV box performance. CUSUM charts, a statistical quality control tool, are used to evaluate the process errors. Thresholds are determined by statistical analysis of a database of "normal operation" data.

APAR and VPACC were evaluated using data from several different sources - an office building, a restaurant, and community college and university campuses, featuring constant- and variable-air-volume systems. Any evaluation using field data must contend with some inherent difficulties: reliance on sensor data to discern the true state of the system, the inability to report a "false positive" (an undetected fault), and ambiguity regarding what constitutes a fault. However, in this case consistent results across diverse testing environments gives a high level of confidence that the FDD tools will perform in an even greater variety of applications. Several faults have been successfully detected and confirmed by building operations staff. Every site has been found to have at least one fault. Even though the sample size is small, these results appear to confirm the hypothesis that faults of the type that can be detected by these tools are common. 
In a parallel study beyond the scope of this report, the FDD tools were embedded in AHU and VAV box controllers and evaluated in a laboratory setting. Follow-on work will require partnering with control system manufacturers to conduct field tests of APAR and VPACC, embedded in their own controller products.

NIST's vision of full commercialization of automated fault detection and diagnostics is one in which APAR and VPACC, along with appropriate parameters and thresholds, are packaged within HVAC control products. In order for this vision to become reality, more work is needed in three main areas. First, it is impractical to expect trend data to be evaluated to determine the necessary parameters and thresholds for each site, as was done in this study. Ideally, sets of robust parameters and thresholds that are effective across specified ranges of applications would be available. Additional field data from a wide variety of systems must be collected in order to determine these robust parameters and thresholds. Also, the current embedded FDD tools are written using generic mathematical functions available in the languages in which the controllers are programmed. Although this approach is suitable for a technology demonstration, built-in APAR and VPACC functions would greatly simplify the task of embedding FDD in a control program. Finally, more work is needed to develop alternative ways to interpret FDD results and deliver this information to the building operator. The most direct approach is to generate an alarm that the operator must acknowledge whenever a rule is satisified (APAR) or a cumulative sum exceeds the alarm limit (VPACC). Refinements to the basic scheme are possible. For example, rather than automatically sending the alarm to the operator, the building control system could highlight, on demand, those devices having experienced the greatest number of alarms in a given period of time. Or, if an automated maintenance management system is used, an alarm could automatically generate an appropriate work order. However, many faults are the result of design or commissioning issues that are beyond the scope of the building maintenance staff. Furthermore, a fault in another piece of equipment, such as an air handling unit, boiler, or chiller, could result in this approach generating a large number of alarms, perhaps overwhelming the operator. A mechanism is needed to resolve multiple conflicting fault reports before reporting them to the operator.

\section{References}

[1] Castro, N.S., Schein, J., Park, C., Galler, M.A., Bushby, S.T., and House, J.M., 2002, "Results from Simulation and Laboratory Testing of Air Handling Unit and Variable Air Volume Box Diagnostic Tools", NISTIR 6964.

[2] House, J.M., Vaezi-Nejad, H., and Whitcomb, J.M., 2001, “An Expert Rule Set for Fault Detection in Air-Handling Units,” ASHRAE Transactions, Vol. 107, Pt. 1: pp. 858-871.

[3] Ryan, Thomas P., 2000, Statistical Methods for Quality Improvement, $2^{\text {nd }}$ Edition, Wiley and Sons, New York. 